Portland State University

PDXScholar

Summer 8-17-2017

\title{
"Are We Building Biking Solidarity": Gendered, Racial, and Spatial Barriers to Bicycling in Portland, Oregon
}

Kyla Jean Tompkins

Portland State University

Follow this and additional works at: https://pdxscholar.library.pdx.edu/open_access_etds

Part of the Sociology Commons, and the Transportation Commons

Let us know how access to this document benefits you.

Recommended Citation

Tompkins, Kyla Jean, "'Are We Building Biking Solidarity": Gendered, Racial, and Spatial Barriers to Bicycling in Portland, Oregon" (2017). Dissertations and Theses. Paper 3834.

https://doi.org/10.15760/etd. 5728

This Thesis is brought to you for free and open access. It has been accepted for inclusion in Dissertations and Theses by an authorized administrator of PDXScholar. Please contact us if we can make this document more accessible: pdxscholar@pdx.edu. 
"Are We Building Biking Solidarity:"

Gendered, Racial, and Spatial Barriers to Bicycling in Portland, Oregon

by

Kyla Jean Tompkins

A thesis submitted in partial fulfillment of the

requirements for the degree of

\author{
Master of Arts \\ in \\ Sociology
}

Thesis Committee:

Amy Lubitow, Chair

Maura Kelly

Miriam Abelson

Portland State University

2017 
(C) 2017 Kyla Jean Tompkins 


\begin{abstract}
Although Portland, Oregon is widely regarded as a "bike friendly" city, its bike equity remains in question. This thesis explores the barriers to biking that women and people of color face in Portland. This research uses feminist geography scholarship to understand how cycling spaces are unequal for marginalized cyclists. Using data from 28 in-depth, semi-structured interviews with infrequent and marginalized cyclists, I found that gender and race inequalities shape their barriers to biking. A hegemonic white, elite, and masculine bike culture controls the domination of cycling spaces. Women's gendered spatial inequalities are shaped by their childrearing demands, geography of fear, and street harassment. Cyclists of color experience a fear of public space due to racial profiling and police violence, and racial spatial inequalities are shaped by Portland's historic and racist city planning that gentrifies and displaces residents of color. Furthermore, intersectional inequalities of gender, race, and class, emerge and illustrate how cycling spaces are built to be unequal. These findings suggest that spatial inequalities in the urban landscape are pervasive in multiple spaces such as bike lanes, and that more research and policy is needed to increase ridership among women and people of color.
\end{abstract}




\section{Dedication}

For Kathy Anne. There are not enough words. 


\section{Acknowledgements}

To have a mentor is truly a privilege, and I have been blessed with more than one. To my advisor, Amy Lubitow, I want to thank you for not only being an exemplary researcher and teacher, but for being a strong woman whom I now model my expectations after. To Ron Barnett, the first teacher to push me past complacency, to rise above my station and expect excellence from not only others, but myself. Ron, I would not be here without you.

To my committee members, Maura Kelly and Miriam Abelson, both of you inspire me to no end. I know a lot of people who call themselves feminists and call themselves researchers, but you two show how you can, and should, be both.

To the sociology department! I have been with PSU Sociology for several years, and it feels more like home now than any other place I've worked. I've never been in such a positive and progressive environment in my life. To Bahar and Kris, for always making me laugh when I felt the craziest. To alumni Cristina Restad and Dylan Waite, who finished their master's here three years ago when I was a wee undergrad. Thank you for encouraging me to go on this crazy journey called grad school, and somehow being here for me still. To Chris Guy, Nate Rochester, and Emily Wiant for starting Sociology Club with me and helping me realize my full data nerdy potential. To Julius McGee, José Padin, Melissa Thompson, and Dara Shifrer: I respect your knowledge, mentorship, and 
caring natures. Thank you for letting me pester each of you relentlessly. Dr. Padin, thanks for your help in securing the legacy of the Fab 5.

To my cohort, whom I swear I dreamed up before I met, you are, collectively, the love of my life. Alexis DeVigal, Rina James, Erin Savoia, and Philip Tostado: my amoeba cohort, we might not get so lucky again. We are a collective consciousness of ducklings. We have many camping trips in our future. At the end of the day, you all are the reason that I have no doubts whether this journey was worth it or not.

To Troy: you have held me together throughout these rough few years. I am astounded by your resilience and patience. You give me strength, and I love you in return. 
Table of Contents

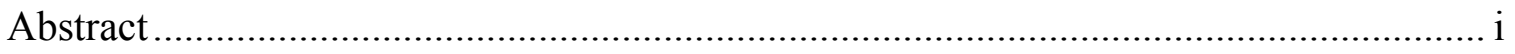

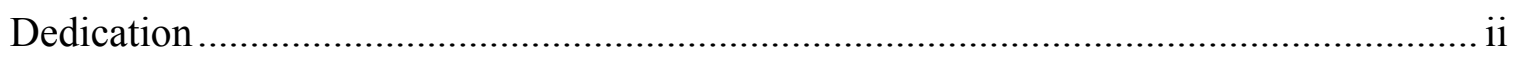

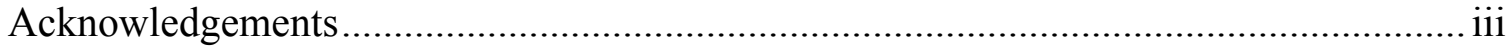

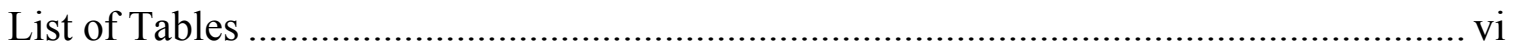

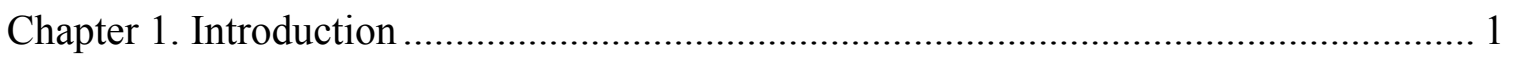

Chapter 2. Literature Review and Theoretical Framework ......................................... 7

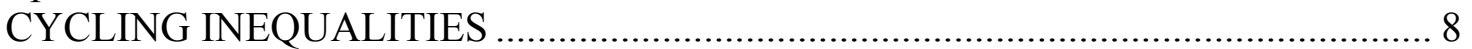

GENDER INEQUALITY: CYCLING AND GEOGRAPHY OF FEAR .................... 9

RACIAL INEQUALITY: CYCLING AND PORTLAND PLANNING .................... 20

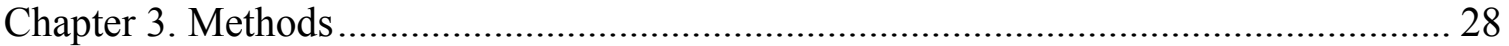

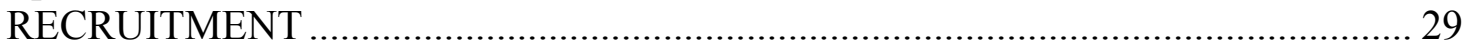

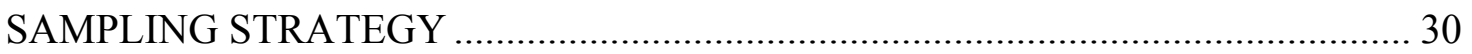

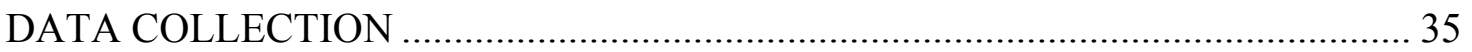

Chapter 4. Findings Part I: Gendered and Racial Spatial Inequalities............................ 39

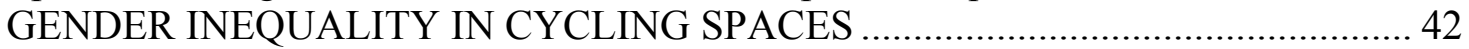

RACIAL INEQUALITY IN CYCLING SPACES................................................ 62

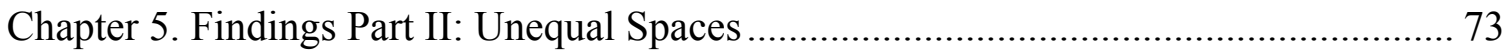

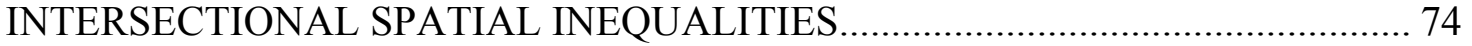

PORTLAND'S RACISM \& HISTORICAL INEQUALITIES IN PLANNING ......... 79

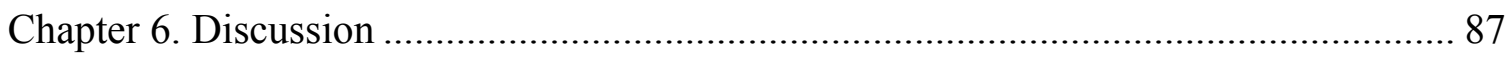

POLICY AND SOLUTION RECOMMENDATIONS .......................................... 91

DISCUSSION: GENDER, RACIAL, AND SPATIAL INEQUALITY WITH

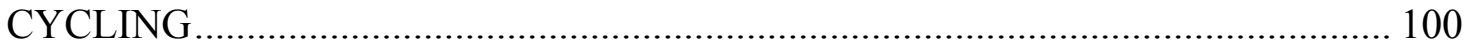

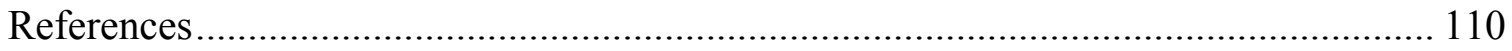

Appendices:

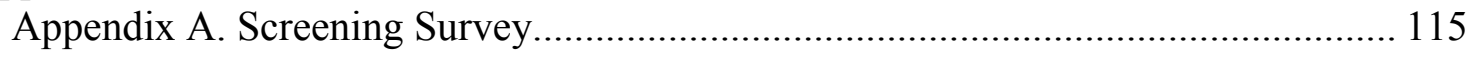

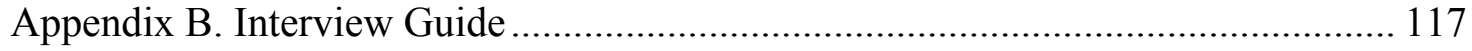




\section{List of Tables}

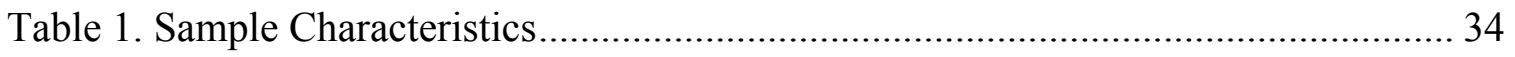


Chapter 1. Introduction

Portland, Oregon is well known as being a 'cycling city.' Most recently, Portland was ranked by Bicycling.com as 2016's third Best (U.S.) Bike City in 2016. In 2012, a Census report revealed that Portland had the highest bicycle commuting rate in the nation at $6.1 \%$ (McKenzie, 2014). Not only is Portland's bicycling scene reputable, it is romanticized by outsiders. In IFC's hit show 'Portlandia,' a satirical sketch comedy show based on the life of Portland residents, cycling is symbolized as the pinnacle form of transport for Portlanders. In one sketch, Fred Armisen's character, wearing bright, summery clothing, a messenger bag, no helmet, and blowing a whistle, rides his fixed gear bike, loudly (and repeatedly) proclaiming, "Bicycle rights!" in a montage of his ride through NW Portland. He quips at random cars with other stereotypical progressive Pacific Northwesterner beliefs such as: "Bicycle rights, go vegan!" The sketch ends with Armisen's character getting his front door chain caught on the inside of his large gauge earring as he attempts to enter his home (still on his bike). Despite the farce of the scene, it illustrates the ideal cycling situation for an urban dweller: plenty of bike lanes, sunny skies, and the freedom to weave undisturbed around cars and traffic. Outsiders can only imagine that upon viewing 'Portlandia' or other exaggerated representations of cycling in popular culture, that Portland is indeed a bicycling utopia. Although cycling in Portland has its perks, albeit exaggerated by Portlandia, not everyone has the freedom to roam as liberated as the 'Bicycle rights!' guy. My thesis will explore how marginalized individuals who ride bikes in Portland are impacted by their socio-cultural environment 
and gender, race, and class inequalities. These inequalities amplify in cycling spaces that are dominated by a hegemonic masculine, elite class, and white cyclist culture.

Ultimately, Portland's cycling scene perpetuates a spatial inequality that negatively impacts women and people of color.

Many people choose to ride a bike because cycling is a healthy, environmentally friendly, and cost effective mode of transportation. Previous research has shown that many physical and mental health benefits are linked to cycling (Garrard et al., 2012a; Huy et al., 2008; Oja et al., 2011; Pucher et al., 2010; Wen and Rissel, 2008). On the population level, Garrard et al. (2012a) suggest that there are broader health implications from certain cycling behaviors such as riding a bike for errands, daily trips, and visiting friends and family, which can be called utilitarian or habitual cycling. Increasing physical activity through utilitarian or habitual cycling has broader and more direct health benefits for many demographic groups (Garrard et al., 2012a). Despite the plethora of benefits that cycling offers, the U.S. still falls behind in cycling rates compared to other industrialized nations (Garrard et al., 2012b). Among U.S. cyclists, women and racial minorities are underrepresented. (Buehler et al. 2012; Garrard et al. 2012b). Moreover, women are shown to face more acute barriers to cycling that remain only partially explored (Aldred et al., 2015; Bopp et al., 2014; Emond et al., 2009; Garrard et al., 2008; 2012b). Although cycling offers many benefits as a mode of transportation to many demographic groups, cycling inequities and the low rates of women and people of color who choose to cycle remain underexplored. 
Researchers have begun the work of exploring what barriers perpetuate low cycling rates among women and people of color, yet these studies largely involve quantitative analyses that do not specify the barriers to groups nor give depth of the issues at hand (Bopp et al., 2014; Dill and McNeil 2013; Emond et al., 2009; Garrard et al., 2012a; Pucher et al., 2011). My research explores the paradox of living in a 'bikefriendly city' and being a woman or person of color who owns a bike but does not ride it habitually; this population reveals underrepresented perspectives on accessibility in a place with renowned cycling infrastructure and climate. This suggests that for my participants, other than accessing a bike or having the ability to ride it, barriers remain that reflect larger systemic inequalities. Although qualitative research does not offer generalizable results, my findings can act as a springboard for further research and policy ideas based on marginalized identity-informed barriers and solutions.

Despite ongoing research that explores rates of cycling, there is a dearth of sociological research on how gender and race, as interconnected marginalized identities, interact or interfere with how individuals experience cycling. There is also a related lack of research identifying barriers (social, economic, and physical) to cycling based on gender and race. The research on cycling equity is developing, but recently more focus has been given to women and cycling rather than people of color and cycling (Bopp et al. 2012, 2014; Steinbach, Green, Datta, \& Edwards, 2011). In this thesis, I aim to bridge the gap between quantitative research on cycling amongst vulnerable populations and feminist research methodology; to do this I endeavored to give voice to marginalized individuals by means of qualitative interviews. I conducted 28 semi-structured, in-depth 
interviews with a diverse sample of women and people of color. I will explain the methods used in depth in the third chapter of this thesis.

\section{Research Questions}

In order to discover the barriers to cycling for women and people of color, my research methodology must allow for participants to have the space to define their issues and experiences. To allow for a depth of themes, I pose two large research questions:

1. How do identities shape the experiences of marginalized individuals who ride a bike infrequently in Portland, Oregon?

2. What are the barriers to cycling related to individuals' marginalized identities of gender, race, and class, and other relevant identities that may emerge?

This thesis will explore how gender and race (among other identities) are interconnected and transform spatial inequality beyond one attributive identity. Linking insights from feminist geography, intersectionality, and public planning research, I argue that women and minorities experience cycling spaces in ways that reflect broader gendered and racial inequity; ultimately revealing how uneven geographies within cycling spaces generate another form of spatial inequality for marginalized groups in public spaces. Overview of thesis

In the next chapter, I review the literature on cycling inequities and relevant issues of gender and race inequality. I begin by examining the current state of cycling disparities. Moving beyond looking at cycling rates with only quantitative data, I examine the literature that looks at women's relationship to cycling, public space, and the perception of threat that women live with daily. I also review literature based on 
Portland's history of racial disparities, including racist public planning, which reflects a racial tension that permeates for people of color cycling in Portland.

In chapter 3, I will explain the methods used. In aiming to use feminist research methodologies to explore cycling inequalities, I used qualitative interviews as a means of giving voice to marginalized individuals. I conducted 28 semi-structured, in-depth interviews with a diverse sample of women and people of color.

My first findings chapter explores how marginalized cyclists experience spatial inequality in cycling spaces which can be attributed to larger systems of racial and gender oppression. I also discuss how childrearing proves to be a salient barrier for mothers in this sample as the gendered norms and expectations of motherhood prevent them from easily accessing cycling. Women and people of color's marginalized and intersecting identities transform their experiences on a bike based on their perception of threat, others' behavior, and a masculinized spatial dominance. I argue that cycling is an activity that represents spatial inequality, or, the amplification of other social inequalities in public spaces. Furthermore, cycling space is dominated by a white, patriarchal order: this is maintained by the presence of a hegemonic masculine, white, upper middle class norm of cyclists in Portland.

My second findings chapter examines Portland as its own unique urban climate for cycling. The data show that cycling is related to larger urban issues specific to Portland. Participants of color connect cycling infrastructure choices to Portland's longstanding issues of gentrification, displacement, and a history of racist city planning. I also argue that Portland fosters spaces that form spatial inequalities by not making city 
planning choices that center around non-white, male, and elite cyclists. Indeed, spatial inequality is created by larger issues of marginalization and oppression, but in turn the city of Portland contributes to unequal spaces through its city planning and bike culture.

In my discussion, I consider how, and why, women and minorities may choose to bike even in the face of significant barriers. Cycling can be a form of empowerment and freedom for women and people of color; it offers a uniquely intimate interaction with public space and health incentives. I review the solutions put forth by my participants and policy implications from the findings and literature. Overall, this thesis find that barriers to cycling are reflective of spatial, gender, and race inequalities. Furthermore, the city of Portland shapes these barriers through a particular kind of urban planning that prioritizes planning for white, middle-class, able bodied men. Despite the many disparities and persistent barriers to cycling and feeling safe in public spaces, participants are generally optimistic about cycling and the potential for changes that would make cycling more inclusive. Still, Portland fosters an exclusive bike culture that reinforces a spatial dominance by masculine, white and elite cyclists. These findings contribute to the literature on gender inequality, racial disparities in urban public spaces, feminist geography, and cycling interventions and equity. 
Chapter 2. Literature Review and Theoretical Framework

The primary objective of this research is to investigate potential inequalities that exist among marginalized cyclists. To properly investigate Portland's cycling equity, I will establish a link between Portland's city planning and how marginalized cyclists interact with public spaces. To do so, I draw from literatures on a) cycling inequalities and barriers to biking; b) feminist geography; c) historical data on racism in Portland planning; d) intersectionality.

I begin this review by highlighting the most recent research on barriers to cycling in Portland, Oregon and display the importance of interrogating whether Portland is "bike equitable" rather than "bike friendly." I then move on to review current data on gender and cycling and consider scholarship within the field of feminist geography which can lend insights into gendered spatial inequality. Next, I focus on the racial context of Portland, a predominantly white city with ongoing challenges related to gentrification and unequal city planning. Through demonstrating how racial oppression functions at the city-level, I aim to build a framework for the arguments I make in my findings chapters. Finally, this review engages feminist writings on intersectionality in order to interrogate the complexity of identity-based inequalities. Following the literature review on theory and empirical data, I will review current policy data towards equitable cycling before moving on to my methods chapter.

These literatures are the foundation for my later argument that cycling spaces are controlled by an elite, white, and hegemonic masculine bike culture; thus, cycling spaces perpetuate racism and sexism for marginalized cyclists by creating barriers that 
contribute to larger spatial inequalities. Because there is a dearth of qualitative research in studies on biking equity, my thesis will contribute to qualitative data on cycling inequalities and spatial inequality.

\section{CYCLING INEQUALITIES}

\section{Current Cycling Data and Portland Cycling Scene}

Portland is an ideal case study for cycling research as it has well established bike commuting rates and infrastructure. Further research in cities such as Portland, Oregon is needed to understand what bars potential cyclists from reaping the benefits of cycling and quality infrastructure. Portland has been called the most "bike oriented" large city (Buehler and Pucher, 2012) in the U.S., and most recently was ranked as the third best cycling city in the U.S. (Bicycling.com 2016). Portland maintains cycling infrastructure that offers opportunities for residents to explore the potentials of cycling more so than cities with more car-oriented infrastructure. Attempts to understand Portland's cycling demographics have already been made. In 2006, Geller originated a typology of Four Types of Cyclists, which was expanded on by Dill and McNeil (2013) to understand cycling attitudes of residents in Portland. Dill and McNeil (2013) found through conducting phone surveys in Portland-Metropolitan area that the majority of the Portland population can be represented as "Interested but Concerned," with the smaller groups being "No Way No How," "Enthused \& Confident," and "Strong \& Fearless." Women are most likely to be found in the "No Way No How" category, but a fair amount are identified as "Interested but Concerned." A utilitarian cyclist is defined as a cyclist who 
has biked in the past 30 days and bikes at least once a month in a typical summer or winter month (Dill and McNeil, 2013). The benefits of further studying cyclists who are "Interested but Concerned" is that they are likely to already own a bike, are curious and interested in biking, but have reservations while they may be cycling or the concerns prohibit them from pursuing cycling. Based on these findings of different types of cyclists, I conceptualize the "infrequent cyclist" as someone who has the potential to be a utilitarian cyclist: respondents who bike infrequently yet own a bike and are physically able to ride, have been exposed to different barriers, and do not already identify as a utilitarian, or frequent, cyclist. My thesis will explore the issues that these cyclists face in Portland, expanding on the participants' cycling concerns characterized by Dill and McNeil's typology (2013), and how barriers are formed according to the race and gender of cyclists. To better inform this study, I will draw from the literature on cycling and gender inequalities, as well as feminist geography to understand women's spatial barriers in the urban landscape.

\section{GENDER INEQUALITY: CYCLING AND GEOGRAPHY OF FEAR}

Although bicycling is well known as a healthy commuting option, gendered disparities in ridership remain. Compared to other advanced industrialized countries, the United States harbors a low number of women cyclists; only Ireland and Australia fall behind in numbers of female cyclists (Garrard, Handy, and Dill 2012b). In the United States, men ride their bikes to work more than twice the rate of women (at .8 percent and .3 percent respectively) (McKenzie 2014). In Portland, despite being known as a high- 
cycling city with reputable biking commuter rates, its cycling population also lacks women representation: of those cyclists who are women, the majority live close to the city center, whereas $10-15 \%$ of women cyclists live outside the parameter of Portland's city center (Garrard, Handy, and Dill 2012b). Many additional studies find that women's cycling ridership is lower than those of male cyclists from many countries (Garrard, Rose, and Lo 2008; Akar, Gulsah, Fischer and Namgung 2013; Aldred, Woodcock, and Goodman 2015).

Cycling inequality is an issue of gender, as there are contributing social factors that discourage women from cycling. In much of the empirical data, we see a divide in gendered attitudes and behaviors towards cycling, and that gender indeed shapes mobilities, such as in the work by Steinbach, Green, Datta, \& Edwards (2011). Steinbach et al. (2011) found that gender disparities exist in attitudes towards (or about) cycling in London: women of middle-class or higher could sometimes adopt assertive attitudes against any potential harassment they faced on their bikes, whereas men, regardless of class status, always embraced an aggressive attitude while cycling. In their study, women found themselves as simultaneously "visible" and "invisible" in cycling: they felt safety in their use of public space by blending into the crowd at times, but they also felt vulnerable and exposed in the public domain where the potential for street harassment or crime is enhanced. Like Steinbach et al.'s (2011) study, Heesch, Sahlqvist and Garrard (2012) found in Australia that the propensity to commute by bicycle was associated with men, and that women cycle less for transport (commuting) than recreation, and less overall than men. Both studies, however, take place outside of the United States, thus the 
cultural norms are not translatable. Bopp, Kaczynski and Besenyi (2012) in their Kansas, U.S. based research found that men have more propensity to cycle, followed with Bopp, Child \& Campbell (2014) expanding to look at the propensity of cycling among women in the Midwestern U.S. They measured active commuting rates, as walking or cycling, of Midwestern women. Despite the noted health benefits, Bopp et al. (2014) still found that rates of active commuting were low among their sample of 706 women. Furthermore, Bopp et al. 2014 excluded adults who did not work outside of the home, which I did not exclude in my study; adults do not need to commute to work to be utilitarian cyclists, and there are many other reasons that an adult can bike such as to run errands. Racial minorities are underrepresented in the research. These empirical data are limited: they have established that women bike less than men, and that women face barriers, but reasons for the gender inequality among cyclists remain unexplored.

Feminist research interrogates the way that society is determined by a patriarchal order of power and domination. As Connell writes in her definition of hegemonic masculinity, "The hierarchy of masculinities is a pattern of hegemony, not a pattern of simple domination based on force," (2005:846). Hegemonic masculinity is culturally embedded as a social construction that determines the behaviors, expectations, and exchanges of men, between men and women; it need not be violently enforced or blatantly observed. Many sociological studies have explored the ways that hegemonic masculinity affects men and women's roles in the workplace, family, gender performance, and many facets of social life (Acker 2006; Epstein 2007; Glenn 1994; Lorber 1994; West \& Zimmerman 1987). While much literature exists on gender 
inequality, and despite some existing research on women and cycling, there has yet to be a study that determines the role that power and domination play in impacting women's cycling habits.

The existing literature on gender and cycling identifies the gender divide amongst cyclists; however, samples are predominantly white throughout the quantitative and qualitative research. Research also tends to focus on individuals that are routine or commuter cyclists, meaning that little research has been done to address potential utilitarian cyclists. The richest data available on women cycling habits are by either cycling enthusiasts or about cyclists in European countries, such as the United Kingdom (most research taking place in London). By addressing a marginalized population of individuals, such as women and people of color, that own a bike and could become avid cyclists, we can better understand the real barriers to cycling among marginalized groups.

Like in the Four Types of Cyclists report, similar research was conducted in Portland in 2012 by the Community Cycling Center (CCC) to understand racial minorities' and low-income populations' barriers to cycling. The "Understanding Barriers Bicycling” 2012 report used a mixed methods approach to establish barriers to cycling among racial/ethnic minorities who ride bikes presiding in Portland. They found that women biked less than men, and identified barriers among their respondents such as cost, lack of group support, lack of information about safety, street safety, and lack of bicycle storage. Their sample consisted of Latino, African, and African American residents, all who had faced these barriers in some capacity. Significantly, $100 \%$ of African American participants named safety as a cycling concern. My thesis will expand on the report by 
Portland's CCC by asking about additional barriers to biking for women and racial/ethnic minorities. From these Portland data, we can determine what further research is needed to understand how race, class, and gender affect cycling rates and inequalities among cyclists. Next, I will look to the scholarship on feminist geography to tie the spatial dynamics of cycling in public spaces to gender inequality.

\section{Feminist Geography}

Landscapes and mobilities are intrinsically shaped by systemic inequalities such as gender. Travel behaviors and options have been established to have gendered dynamics in feminist geography research. Gender inequality is pervasive in that it shapes institutions, day-to-day activities, and the use and access of space. Examining travel habits based on familial patterns is one way to evidence gendered spatial inequality: while men have longer, but direct, travel routes to and from work, women have shorter but more complicated variations of trips throughout a typical day. Often, women's travel behavior includes duties that are typically feminized such as child rearing, shopping, medical visits, and other tasks associated with familial and domestic upkeep (Creswell and Uteng 2008). Furthermore, power dynamics play out through mobilities in interconnecting aspects of spatial dynamics: how people move geographically, their potential for undertaking movements (motility) as it is lived and experienced, the meanings ascribed to movements, and practice (Creswell and Uteng 2008). This understanding of gendered mobilities should be applied to cycling research to examine the gendered implications of how, when, where, and why women do or do not cycle. 
Furthermore, mobilities vary by gender and territory: in urban settings, residents may choose walking or cycling easier than in rural settings for denser populations, the closer placement of resources, and distribution of public space. (Miralles-Guasch, Martínez Melo, Marquet 2016). Gender inequality is reiterated from systemic injustices to phenomenological experiences like embodiment and the way that actors move relative to the surrounding physical space. Longhurst contends that, just as spaces are embedded with culturally constructed norms, bodies are "increasingly understood as surfaces on which values, morality, social laws, and even cities are etched" (2005). Grosz (1992) argues that bodies should be understood as having a mutually constitutive relationship with cities, a linkage or interface between the two, which can extend to gendered understandings of body with the city. In this understanding, city spaces can be embedded with cultural norms which extend to how gender is constructed for those existing within those spaces. Portland can be understood as having its own culture and its cycling spaces will reflect that culture, and those riding in those spaces will embody and represent the culture. Women's lives are shaped by the city they live in, city portrayals in the media, and our own imagination of what cities are (Preston and Ustundag 2005). Despite overcoming some distance and economic barriers for women in the suburbs and central city, inequities to women's liberal mobilization persist through facets such as transportation (Preston and Ustundag 2005).

Cycling can be placed at the intersection of occupying public space while moving through it at a quick pace; while cycling might grant agency and speed to bike riders, it remains a vulnerable position to be in compared to motorized vehicles, which encase the 
human body and protect their inhabitants, while also granting greater speed and road access. One might be able to feel safer against crime or violence on a bike as compared to walking because of the speed it provides, as well as agency to access spaces that cars cannot such as sidewalks or bike paths. Conceptually, it is more helpful to compare cycling to walking as walking is another form of mobility that puts the human body in a vulnerable position. As I will discuss ahead, women and men have different levels of fear when interacting with their public space through walking; more research should expand on how the speed and agency of a bicycle may alter the fear (or lack thereof) individuals feel when mobilized and accessing public space.

Cycling is also unique in that, unlike walking, one does not have physical access to potential defensive mechanisms such as weapons to protect oneself against criminals when riding a bike. People may make decisions on what neighborhoods and spaces they enter based on their form of mobility; the same person may choose to access different public spaces or routes depending on whether they are walking, driving, taking public transportation, or cycling. Due to the intersection of vulnerability and agency that riding a bike provides, and my research interest in understanding how gender and racial identity may alter access to and experiences of cycling, this research benefits from existing research in feminist geography. In this section I will outline the theoretical and empirical contributions from work centered on gender and public space as well as the fear of victimization that women face when accessing public spaces. From the literature, I will establish a basis for a gendered spatial inequality argument that will be expanded to cycling spaces through my research. 
Feminist geography, the subfield of geography dedicated to analyzing gender differences in geographical space, has recently critiqued the lack of intersectionality in its theoretical considerations (Valentine 2007). Like other social sciences, human geography focuses on human behaviors and demographics, thus there is a need to comprehensively include the concept of intersectional identities as a base point for marginalized groups. What we gain from feminist geography is the theoretical understanding that how we understand human behavior is contingent upon how we occupy space; more specifically, we gain understanding of how different groups relate and interact with public and private space, including the inequities of access to spatial locations. Feminist geography and the use of intersectionality in research can have a mutually beneficial relationship as Valentine (2007) illustrates. She contends that "space and identities are co-implicated," and that individual identities interact with each other in different ways that expose the dominant spatial orderings of who belongs, or doesn't belong, where, and that particular spaces can reveal how power operates and how particular inequalities are systematically (re)produced (2007:19).

Following Valentine's (2007) synthesis on how intersectionality should be implemented into feminist geography research, we can advance the discussion towards the spatial significance of how certain identities operate on a bicycle. Women's role within the patriarchal order of society leads to the research question primarily pursued in this project which reflects larger questions that feminist geography tackles: do women have less access to space? Are certain spaces masculinized or feminized? How do women "do" gender in different ways to compensate for differing power and access levels 
through various spaces? Again Valentine speaks to the different ways identities are "done" depending on the space and the multiplicity of oppression: "When individual identities are "done" differently in particular temporal moments they rub up against, and so expose, these dominant spatial orderings that define who is in place/out of place, who belongs and does not" (2007:19). Women have different obstacles when interacting with space than men do, and riding a bike is no exception to the spatial power and access differentials. As women bike less than men, it is critical to question whether or not women choose to bike less due to their experiences of occupying space while cycling. To ride a bike is to place one's body in an inherently public domain, exposed to the elements, other people, and power differentials found in space. I will critically analyze cycling as a feminist issue drawing from the literature on occupying public space and inhibitors women feel, such as fear when placing their bodies in certain spaces.

\section{Fear and Threat of Victimization in Public Spaces}

To further analyze the fear or threat of victimization that women and people of color face in public spaces, criminology complements the research found in feminist geography by investigating the resulting fear and victimization that women face due to spatial inequality. When analyzing women's experiences riding a bike through public space, it is necessary to look into their feelings and experiences of safety being exposed to infrastructure, elements, and a variety of neighborhoods. Women tend to self-exclude themselves from certain spaces due to perceptions of risk and fear (Pain 1997, 2001). Furthermore, women may be limited in their access to cycling if they fear victimization of violence, crime, sexual assault, or harassment, while placing their bodies in public 
spaces without the comfort of a private motorized vehicle that many women rely on in industrialized countries. In this section, I will elaborate on the previous literature looking at how gender and fear of victimization interact in regards to how individuals interact with, or have access to, urban public spaces. I will henceforth refer to the fear, or threat, of victimization, violence, crime, sexual assault, and harassment as 'perception of threat' as the terminology widely ranges in the literature.

Men, though more likely to experience less fear of victimization as women (Schafer, Huebner, and Bynum 2006), have their own unique fears of victimization when accessing public spaces. In her call for research centered on issues of gender and public space, Valentine (1989) contended that women's fear of men and violence, and inhibited occupation in public space, perpetuates and maintains male-domination and patriarchy. Abelson (2014) analyzes the unique experiences of transmen and how their fear of violence shapes transmen's masculine practices and found that following their transition, transmen no longer have the same fears of violence, such as walking home alone at night or being raped, that they once had as women: "As their geography of fear shifted, this allowed them increased access to public space.” (Abelson 2014:558) This case furthers the demand for understanding how gender identity can transform and be in flux with feelings and relations to public space. In that same vein, people of color may face different fears than white people when accessing public space. For example, Black men's mobility patterns are altered in unique ways by police presence and a higher rate of being pulled over by a police officer for Driving While Black. (Nicholson 2016) 
The literature points out that avoidance behaviors restrict women's mobilities (May et al. 2009), May et al. find further evidence of the gendered differences predicting threat of victimization (2009). In their case, women's threat of victimization is affected by a rationality of avoiding specific areas (that they feel they could be victimized in) and engaging in defensive behaviors to protect themselves (May et al. 2009). Women also face acute forms of street harassment that imply a perception of threat due to sexually aggressive patriarchal interactions (Tran 2015). Consequently, women who cycle through public spaces should be considered risk takers who may or may not be aware of certain spaces (or time of day) where their fear of victimization increases. Green \& Singleton (2006) similarly conceptualize this negotiation of space and place through understanding leisure; they find that spatial exclusion is a key aspect of this negotiation and that it benefits some women over others in terms of who defines where as a 'safe space' (2006). Space is argued in their literature review as "gendered, sexualized, classed and racialized; and ease of access and movement through space for different groups is subject to constant negotiation and contestation, and is embedded in relations of power" (Green \& Singleton 2006:859). Public space in Western society has long been claimed by white, heterosexual men who have dominated, controlled and excluded other groups through the exertion of an aggressive 'gaze' or the use of violence (Green et al., 1990, Lupton, 1999; Pain, 2001 as cited in Green and Singleton 2006). Following that, we can understand cycling as another activity where women must move through masculinized public space, more specifically as bike lanes and roads through Portland. It is in this spirit that advocacy for 
women's access to space must be further implemented and their specific barriers further studied to inform policy interventions.

\section{RACIAL INEQUALITY: CYCLING AND PORTLAND PLANNING}

Along with gender disparities, this thesis will interrogate the underexplored racial differences among cyclists in the United States. The literature on the racial diversity of cycling rates is limited beyond few quantitative data. In a report for the U.S. Census Bureau, McKenzie (2014) used data from the American Community Survey 2008-2012 to explore the social and economic population differences among commuters who walk or bike to work. Black workers from this sample had the lowest ridership rates in the nation at .3 percent. Those who identified as two or more races had rates of .8 percent, and Hispanic/Latino commuters represented .7 percent of riders. These data point to existing ridership disparities between racial minorities, yet the mechanisms of racial differences remain in question. Thus, my thesis will investigate racial disparities through pursuing qualitative depth in explaining potential barriers to cycling.

The story of racial disparities of ridership remain even less explored in the context of Portland, Oregon. The "Understanding Barriers to Bicycling" report established that Portland cyclists of color have safety concerns, but the depth of those issues have yet to be investigated further (Community Cycling Center 2012). The need for more information on who is riding in Portland is evidenced by its largely white population, which was most recently reported as $72.2 \%$ white (non-Hispanic/Latino) (U.S. Census Bureau, 2010). Furthermore, white and nonwhite populations occupy different areas of 
Portland with communities of color facing unique economic disparities based on urban planning. Blacks and Latinos who live in segregated neighborhoods in Portland are perpetually at risk of displacement and have less access to amenities such as transit and active commuting options like cycling (McKenzie 2013). Moreover, communities of color in the Portland area are disproportionately behind in terms of socioeconomic wellbeing and income. As reported in 2008 in Multnomah County, individuals of color earn just over half of the mean annual income $(\$ 16,635)$ that whites earn $(\$ 33,095)$, and have a $35.7 \%$ higher unemployment rate than whites. Housing and economic disparities are larger in Portland than other major U.S. cities. This sets up communities of color in Portland to be more economically vulnerable and disadvantaged when their housing is being priced towards white, affluent families. (Curry-Stevens, Cross-Hemmer, and Coalition of Communities of Color 2010).

Portland's current racial climate is impacted by a tense and deep history of redlining, discrimination, and more recently, displacement and gentrification that disproportionately affect low-income residents and communities of color (Gibson 2007). Many neighborhoods within NE Portland, or the Albina District, have been and are currently in the process of gentrifying (Gibson 2007; Shaw and Sullivan 2011; Sullivan and Shaw 2011; Sullivan 2007). For example, the demographics and business ownership have been changing drastically since the 1990s when whites rapidly began to reclaim housing in the Black Albina neighborhoods. Black business corridors transformed into the "Alberta Arts District," and Blacks were forced to leave at such a rate that they were no longer the primary inhabitants (Gibson 2007). Portland's diversity is shrinking in the 
last decade as people of color have been forced to move from the inner and now costly, gentrifying neighborhoods of Portland to the outer, more affordable neighborhoods. (Hannah-Jones 2011). Portland has made choices such as new developments, bike lanes, and other investments that have are linked to ongoing dynamics and trends related to gentrification and displacement (Gibson 2007; Lubitow and Miller 2013).

Recently, issues of race and gentrification specific to bike infrastructure have arisen in Portland's public discourse. In 2013, Lubitow and Miller conducted research on community response to contested bicycle way planning during the midst of the North Williams Traffic Safety Operations Project. Lubitow and Miller participated in public meetings facilitated by the city in response to the addition of a major bikeway placed in a historically Black neighborhood (2013). As the city planners developed a new bike-way on North Williams Avenue, the African American community surrounding the area pushed back on the development, ultimately forcing Portland city planners to "confront issues of gentrification and history of exclusionary planning policies and practices" related to Northeast Portland (Lubitow and Miller 2013:122). In the end, more people of color were brought into the planning process to make the bikeway outcome more inclusive towards serving all communities, but the question of the bikeway's role in further gentrifying and displacing the neighborhood remains. Lubitow and Miller's research displays that more attention must be paid to the marginalized communities in Portland and other cities. This includes raising the question of whether or not infrastructure is a mechanism of gentrification, whose benefits accrue to more privileged groups; creating further disparities in access to space, and cohesiveness of community, 
for people of color. As Gibson (2007) and Lubitow and Miller (2013) note, exclusionary practices have long been implemented by the city ignoring the voice of the African American community in Northeast Portland. New biking infrastructure can be claimed as a public good by city planners or perceived that way by citizens, yet to those who face injustices in city planning, bike lanes are contested (Lubitow \& Miller, 2013). To further the discussion on inclusionary policy and procedures for advancing city development and sustainability, I will look deeper into the issue of attitudes towards bike lanes in Portland and highlight whether communities of color have equitable access to cycling.

The data on racial disparities in cycling rates, socioeconomic status, and displacement related to gentrification and urban planning makes for a pessimistic view of cycling for people of color in Portland. What Lubitow and Miller (2013) show us is that city planners in Portland may be receptive to including the priorities of people of color, but also that citizens and scholars should remain skeptic: when city plans are made under a guise of sustainability or a public good without first questioning the equitable access to new and intrusive infrastructure, it suggests that Portland may be facilitating change that perpetuates unequal spatial access. As Gibson shows, Portland's history of city planning has never upheld the wellbeing of African Americans (2007). These data lead me to question how the city of Portland shapes the spatial inequality that cyclists of color may face due to larger issues of urban planning.

To investigate Portland's bike culture and accessibility to cycling for marginalized populations like women and people of color, it is necessary to be guided by theory that properly measures the many identity dynamics potentially at play. Because 
Portland is a historically white-dominated city and cycling is a male-dominated activity, both gender and race are important to questioning cycling trends and access in Portland. To get to the root of inequalities and to supply voice to perpetually silenced and oppressed peoples in the United States, I will utilize intersectionality to examine cycling inequalities in Portland, Oregon.

\section{Theories of Intersectionality}

Second wave feminist scholarship has previously been exclusive of women who are not white or middle class. When Kimberlé Crenshaw, a Black woman scholar, wrote her piece on the need for intersectional scholarship in 1991, the need for correcting popular feminism became clear. Since then, feminist research has taken on the critical approach of intersectionality, first coined by Crenshaw in 1991 and further theorized by Patricia Hill Collins. Since this evolution, feminist scholars know that oppressed identities cannot be isolated, but intersect and multiply to form unique forms of domination and marginalization. The strength of intersectional theory is to reveal how multiply-marginalized people hold unique experiences based on issues of gender, race, and class, as well as other social relationships (Choo and Ferree 2010). Patricia Hill Collins offers:

Intersectionality refers to particular forms of intersecting oppressions, for example, intersections of race and gender, or of sexuality and nation. Intersectional paradigms remind us that oppression cannot be reduced to one fundamental type, and that oppressions work together in producing injustice. (2000:18)

As Collins explains, intersectionality is not a sum of oppressed identities interacting, but rather that oppressed identities multiply to produce unique social locations. These unique 
locations of intersectionality create unique dimensions of inequalities for marginalized groups; in my study this will be examined at the level of barriers to cycling. If we were only to research those commonly associated with bike riding (white men), then we would be ignoring issues of bicycle inequity among women and people of color.

Although intersectionality is utilized by many feminist scholars, there are many complexities and various approaches to intersectional analyses. McCall (2005) outlines three approaches to the complexity of intersectionality to distinguish different merits and methodological tactics to researching intersectional units of analysis. She organizes each approach by its categories: anticategorical, intracategorical, and intercategorical.

Following the three approaches to the complexity of intersectionality by McCall (2005), my research is informed by the intercategorical (or categorical) complexity approach. In short, this approach looks at multiple intersections of social relationships in comparison to other intersections, and thus analyzes and compares multiple groups simultaneously. This approach interrogates the boundaries of identities and relationships and emphasizes the inequalities that result and perpetuated from the intersections. The intercategorical approach is well-suited for my research in that it recognizes the different identities and social groupings that belong to one person, and serves to compare the salience and interdependency of multiply-marginalized identities without separating them. The intercategorical approach in my research investigates the salience of each identity for specific barriers to cycling without demanding a hierarchical ordering of oppressed identities. 
This theory is well-suited towards pursuing the research gap in addressing bicycle equity in the United States because it focuses on disparities among marginalized populations as they play out in activities that groups form under, such as cycling. Using this framework, we can further understand inequalities and barriers among cyclists by identifying their interlocking marginalized identities such as gender, race, class, sexual orientation, nationality, and other identities, and how their experiences vary. For my purposes, I will be examining how cycling spaces are built to multiply oppress marginalize cyclists and reflected in the urban landscape.

\section{Conclusion}

In this chapter I reviewed previous literature related to cycling and spatial inequalities across gender and race. First, I established the relevant data on cycling disparities in Portland, namely among women. I explored the existing literature on women and cycling and suggested that feminist geography can glean insights into spatial cycling inequality for women that has been underexplored. I then established that racial disparities are underexplored in cycling research in general, and suggested that Portland contributes to cycling inequality among people of color due to racially driven city planning and processes of gentrification. Finally, I reviewed the theory of intersectionality, which drives this research to examine intricate and intersecting forms of inequality for marginalized cyclists.

This review will serve to support my argument that cycling is an issue of spatial inequality for marginalized cyclists, including women and people of color. Spatial inequality is mechanized by a) a hegemonic masculine cycling culture that perpetuates 
women's geography of fear and b) people of color's experiences with unequal urban planning. Issues of cycling equity are related to spatial inequality which amplifies gender and race inequality: ultimately, intersectionality can illustrate the complexities of spatial inequality for marginalized individuals. The following chapter will explore the methods utilized to answer the research questions and explore the depth of the issues illustrated here. 


\section{Chapter 3. Methods}

For this research, I conducted 28 in-depth, semi-structured interviews with women and people of color who bike infrequently in Portland, Oregon. I chose in-depth interviews as my method to give voice to participants who are underrepresented, as well as to gather rich, complex data that is missing from the literature on cycling. The majority of the interviews took place between March and August of 2016 in the Portlandmetropolitan area of Oregon, while the last several interviews took place in the following fall and winter, ending in February 2017. The initial recruitment season was opportune as Portland cyclists may prefer to ride, or consider riding, more often in the spring and summer rather than the primarily cold and rainy fall and winter months in the Pacific Northwest. Subsequently, participants were more difficult to recruit in the fall and winter. Before being selected for an interview, respondents took an online screening survey to sign up for participation. Interviews were scheduled for a time and location convenient for participants, such as study rooms in neighborhood libraries, quiet spaces at city parks, or my office in downtown Portland at Portland State University. Prior to the interview, participants were asked to complete a face sheet with demographic information which expanded on the screening survey information; these face sheets were kept confidential and secure in a locked office. Interviews usually ranged from 30 to 90 minutes, however one interview lasted up to 120 minutes. Purposive stratified sampling, as well as snowball sampling, was utilized to select participants based on their gender, race, and frequency of riding a bike. 
The research aimed to represent a diverse sample of women and racial minorities (henceforth referred to as people of color). Although many participants were women, men of color were also included to understand their unique experiences. The final sample contains 13 women of color, 9 white women, 2 genderqueer individuals ( 1 white, 1 of mixed race), 1 trans man, and 5 men of color.

\section{RECRUITMENT}

\section{Online/Fliers}

To attract participants, a flier was drafted with information about the study, a graphic of an African American woman with a bike to illustrate the goal representation of people of color, and an incentive was listed: a $\$ 25$ gift card to a local grocer, Fred Meyer. I primarily recruited participants through Facebook pages and groups and with fliers posted in public buildings such as libraries and local college campuses. Recruitment came with certain challenges, as women and people of color are underrepresented as cyclists, and many groups of cyclist that I could more easily recruit from are typically dominated by avid cyclists who would not have fit the research criteria. Community Facebook pages and groups, Facebook groups revolving around racial and gender justice and inclusion, and a few beginner cycling-orientated Facebook groups were recruited from to allow for those who are less interested in cycling-centered communities to participate. Men of color were anticipated to be an especially difficult sample to access, which is where snowball sampling was attempted the most. To navigate these recruitment challenges, many different Facebook groups were approached, I posted fliers at several 
public buildings, and several months were allowed for recruitment. White women were easily accessible to interview as the Portland metro area is primarily white. Because biking is a popular topic and activity in Portland, finding white women that own a bike and have an interest in biking yielded a larger and quicker sample than people of color. Of the 101 people that took the online screening survey, $61 \%$ were white, including one white man (the rest being white women). The recruitment flier included information about the study, expectations of the interview, and the screening survey listed as a web link at tinyurl.com/psubikeresearch, where interested participants fill out questions about their gender, race, and number of bike trips to ensure they fit the qualifications [See screening survey in Appendix A). Participants were selected from those who completed the screening survey and met the sample criteria. Many people who completed the online survey were invited to be interviewed but did not respond to the two e-mails sent from the research e-mail account (psubikeresearch@gmail.com).

\section{SAMPLING STRATEGY}

\section{Stratified}

Purposive stratified sampling was used to target participants who met the criteria of a marginalized and infrequent cyclist, and to ensure a diverse sample of gender and race demographics. My sample was purposive in that I sought specific gender and race groups who biked a limited amount, and stratified in that I aimed to collect different subpopulations to represent gender and race categories. The online screening survey collected demographic data and was used for specific sampling selections rather than 
random or unlimited sampling. I chose the web-based survey software Qualtrics as the screening survey tool. Throughout recruitment, I cross-checked responses incoming from Qualtrics with the evolving demographic table (see Table 1 for finished table). The original goal for the sample was a three-way split of white women, women of color, and men of color (10/10/10). I achieved a stratified sample of these three targeted groups, although without a perfect three way split but still including various marginalized cyclists.

\section{Snowball Sampling}

In addition to using fliers and Facebook, I used snowball sampling to recruit participants. After many interviews, I asked participants of color if they knew any other people of color who ride bicycles. I then followed up after the interview with a thank-you note and an attached recruitment flier via e-mail. Occasionally, participants said that they knew someone who would meet the inclusion criteria and that they would refer them to me or my screening questionnaire, yet I procured an interview with only one person, that I know of, through snowball sampling.

\section{Inclusion Criteria}

The first criteria for participants' inclusion in the research was to be a selfidentifying woman, woman of color, or a man of color. White women were welcome to participate, but white men were not invited. The justification for the gender and race requirements are to maintain an intersectional lens while understanding marginalized groups; because of white men's position of privilege and prominence in cycling culture, this research provides a unique opportunity to give voice to the marginalized groups of 
women and people of color. White women were welcome to participate, but men had to be a person of color to do so. Individuals who self-identified as women, transgender, or outside of the gender binary were welcome to participate.

The other criteria were that participants must own a bike and use it "infrequently" (defined in this study as one to five times a week on average), to live in the Portlandmetro area, and to be 18 years of age or older. As it were, some participants were confused by the number of times a week they were "allowed" to bike to be eligible for the study: during these encounters, I simply told interested participants who met the other criteria that, as long as they were not cycling every day, they could average out their number of bike trips per week to the whole year and qualify.

I focus this research on the population of infrequent cyclists, or those who bike sometimes, but not habitually or as a main mode of transportation. Infrequent cyclists may face barriers towards potential to become utilitarian cyclists (those who do bike habitually and to various places), yet still face barriers to cycling. Infrequent cyclists should be understood as having the physical capability (such as ability to use a bike and owning a bike) to cycle, but due to either choice or barriers, they do not ride their bikes habitually. To further clarify the concept of the infrequent cyclist, I contrast the cyclist who bikes infrequently and may face to barriers to biking with "utilitarian cyclists:" we used the Four Types of Cyclists typology ${ }^{1}$ in Portland. Dill and McNeil (2013) describe utilitarian cyclists as "cyclists who had cycled at least once in the past 30 days for

\footnotetext{
${ }^{1}$ The Four Types of Cyclist typology was originally developed for the Portland Bureau of Transportation (PBOT) by Roger Geller (2006), and elaborated on by scholars Dill and McNeil (2013). We borrow the conceptualization of the utilitarian cyclist from Dill's analysis. Their research will be elaborated on in the literature review section of this thesis.
} 
transportation and usually cycled at least once a month for transportation in a typical summer or winter month" (2013:2387). Following this for my sample, biking could not be a part of the respondent's daily routine, depended on as a primary mode of transportation, nor utilized to complete common errands or trips unless it is infrequently. The requirements to be infrequent cyclists are to ensure that participants had the potential to see what barriers to cycling were stopping them from becoming more frequent, or a utilitarian, cyclists. The infrequent cyclist is adapted from the utilitarian cyclist and treated as "potential utilitarian cyclists" who we look at through the lens of what stops them from broadening their cycling habits.

\section{Sample Demographics}

This sample contains 13 women of color, 9 white women, 2 genderqueer individuals, 1 trans man, and 5 men of color. The following races were represented: white, Black/African American, Hispanic/Latino, Native American, with several participants identifying as mixed race. Most participants were women. The participants ranged in age from 19-60. Level of education varied, but all participants were educated in some capacity, with most individuals holding some sort of college degree ranging from associate to graduate degrees with the rest holding high school diplomas, vocational/trade certificates, or some college. All but one participant was employed either part-time or full-time, with some participants holding multiple part-time positions. Various occupations were represented including receptionists, social workers, service industry clerks, freelance artists, and science and industry occupations such as engineers. See table 1 below for full participant demographic information. 
Table 1. Sample Characteristics

\begin{tabular}{|c|c|c|c|c|c|}
\hline Pseudonym & Employment & Age & Gender & Race & Education \\
\hline Janet & Part-time & 43 & Female & White & Some college \\
\hline Margaret & $\begin{array}{l}\text { Part-time }(2 \\
\text { jobs })\end{array}$ & 27 & Female & White & Graduate degree \\
\hline Jade & Full-time & 38 & Female & White & Bachelor's degree \\
\hline Elizabeth & Part-time & 60 & Female & White & Graduate degree \\
\hline Mary & Unemployed & 57 & Female & White & Graduate degree \\
\hline Julia & Full-time & 39 & $\begin{array}{c}\text { Femme } \\
\text { Genderqueer }\end{array}$ & White & Graduate degree \\
\hline Robin & Full-time & 55 & Female & $\begin{array}{c}\text { Multiple: Black/African } \\
\text { American, Hispanic or } \\
\text { Latino }\end{array}$ & Graduate degree \\
\hline Rosa & Part-time & 22 & Female & $\begin{array}{c}\text { Multiple: Hispanic/Latino, } \\
\text { White, Mixed }\end{array}$ & Some college \\
\hline Katie & Full-time & 28 & Female & White & $\begin{array}{l}\text { High school } \\
\text { graduate/GED }\end{array}$ \\
\hline Velia & Full-time & 36 & Female & Hispanic/Latina & Bachelor's degree \\
\hline Evelyn & Full-time & 42 & Female & White & Bachelor's degree \\
\hline Peter & Full-time & 45 & Male & Black/African American & Some college \\
\hline Manuela & Full-time & 31 & Female & Hispanic/Latina & Bachelor's degree \\
\hline Jordan & Part-time & 29 & $\begin{array}{c}\text { Female } \\
\text { Genderqueer }\end{array}$ & $\begin{array}{c}\text { Multiple: Hispanic or } \\
\text { Latino, Black/African } \\
\text { American, Alaskan Native } \\
\text { or American Indian }\end{array}$ & Some college \\
\hline Miguel & Full-time & 29 & Male & Hispanic/Latino & Some college \\
\hline Ana & Full-time & 30 & Female & Hispanic/Latina & Graduate degree \\
\hline Nicole & Full-time & 26 & Female & White & Bachelor's degree \\
\hline Carol & Part-time & 42 & Female & Latina/White & Bachelor's degree \\
\hline Angela & Full-time & 36 & Female & White & $\begin{array}{l}\text { Trade/vocational/t } \\
\text { echnical training }\end{array}$ \\
\hline Carla & Yes & 28 & Female & $\begin{array}{c}\text { Multiple: Black/African } \\
\text { American, Hispanic or } \\
\text { Latino }\end{array}$ & Some college \\
\hline Simone & Full-time & 45 & Female & $\begin{array}{c}\text { Multiple: Black/African } \\
\text { American, Alaskan Native } \\
\text { or American Indian }\end{array}$ & $\begin{array}{l}\text { Trade/vocational } / \mathrm{t} \\
\text { echnical training }\end{array}$ \\
\hline Janae & Full-time & 46 & Female & Black/African American & Associate Degree \\
\hline
\end{tabular}




\begin{tabular}{|c|c|c|c|c|c|}
\hline Tara & $\begin{array}{c}\text { Part-time } \\
\text { (unpaid) }\end{array}$ & 32 & Female & American Indian & Associate Degree \\
\hline Helen & Part-time & 31 & Female & Black/African American & Bachelor's degree \\
\hline Aneisha & Full-time & 47 & Female & Black/African American & Graduate degree \\
\hline Marcus & Full-time & 40 & Male & Black/African American & Associate Degree \\
\hline Demetrius & Part-time & 19 & Trans Male & Black/African American & Some college \\
\hline Samuel & Full-time & 27 & Male & Hispanic/Latino & Bachelor's degree \\
\hline
\end{tabular}

\section{DATA COLLECTION}

During the interviews, I addressed a range of topics about cycling with the participants: biking behavior, relationships to cyclists and the city of Portland, perceptions of gender and race's effects on cycling, barriers to cycling and motivations for cycling. The interview guide was carefully crafted to start the conversation off lightly to build rapport and progress to more significant issues; I first asked participants how long they have lived in Portland and what kind of bike they had which led into their biking routine and behavior and progressed to asking more sensitive questions such as how their gender and race shaped their experiences. The interview finished with a section on barriers to biking and questions specific to participant's perspectives on potential Portland-specific interventions and policies. To see the complete interview guide, see Appendix B.

Because I also own and ride a bike in Portland, there are multiple relevant identities at play. I was able to follow along easily with the participants' references to Portland roads, bike lanes and places, and could relate and empathize with them allowing for easier data collection and analysis. This research may be influenced by my identity as a white woman. As a woman, I anticipated that the relevance of my identity would assist 
participants in feeling comfortable in sharing marginalization in some capacity, and I successfully connected with the participants on shared knowledge and experiences. Still I pursued building a rapport with each participant with a special emphasis on giving space and voice to the people of color who participated. Many times white privilege and Portland's exceptionally white population came up in conversation and I attempted to bridge the gap by acknowledging the white privilege and racism in Portland.

\section{Data Analysis}

Interviews were audiotaped and transcribed by myself and a professional transcriptionist, referred and hired by my thesis chair, Dr. Amy Lubitow. Files of transcriptions are kept in a secured space to maintain anonymity and confidentiality. Pseudonyms have been used for all participants. The qualitative coding software Dedoose was used to code and organize themes and excerpts from transcribed interviews. Dedoose allows for a hierarchical category system (Thomas 2006) which meant I was able to create and link codes primary codes with subcodes (or: parent and child codes) based on associations from the emerging themes. Because this research is exploratory, I did not begin the coding process with any preliminary themes but let the data expose its own themes, following an inductive analytic strategy. The merits of the inductive analysis approach are many: qualitative researchers are able to capture raw data into a summary format, draw clear links between the research objectives and findings in a transparent fashion, and then develop a theory about the "underlying structure of experiences or processes that are evident in the text data" (Thomas 2006:238). Following Thomas 2006, I used a five-step approach to inductive coding. First, I prepared the raw data files which 
I imported to Dedoose for data cleaning. Second, I did a close reading of the text to further my familiarity of the content. Third, I identified and defined the themes to create coding categories. Fourth, I allowed for overlapping codes and ensured that uncoded text was not relevant to the objectives of my research. Finally, I continued revision and refinement of the coding categories before exporting the coding outputs for final consideration and selection of appropriate quotes to convey the core themes (Thomas 2006: 242).

Several themes were identified during the data analysis. First, primary codes such as gender, race, socioeconomic status, barriers to cycling, positive experiences, and negative experiences were applied to the data. I then recoded the transcripts with the previously mentioned primary codes and added subcodes such as "discrimination" and "white privilege" for the parent code "race" and "sexual harassment" and "child rearing" for "gender". Broadly speaking, themes include barriers to cycling and issues of gender and race inequality on a bike. More specific issues emerged such as safety and harassment, issues of child rearing, criticisms of Portland bike culture's exclusivity, and critiques and praises of infrastructure. A large theme emerged from women's reports of a relationship to people and space around them on and off the bike: these many excerpts led to a theme of spatial inequality. Spatial inequality also reflected the marginalization and exclusion that people of color feel in Portland and its intersection with gender, mainly for women of color. Aside from racialized and gendered barriers to cycling, participants often listed barriers to cycling that related beyond the identity-level, including infrastructure critiques and workplace concerns. I will elaborate on the theme 
of gendered, racialized, and classed spatial inequality in my first findings chapter after analyzing the data. In my second chapter, I will explore the physical and infrastructural issues reported by infrequent cyclists in Portland. 
Chapter 4. Findings Part I: Gendered and Racial Spatial Inequalities

This chapter will explore how gender and racial oppression informs the experiences of infrequent and marginalized Portland cyclists. My findings show that barriers to cycling for women and people of color are shaped by broader social and cultural inequities. Thus, cycling inequalities exist due to the persistence of gender and race inequality reiterated through spatial dynamics in cycling spaces. This section aims to answer the research questions:

1. How do identities shape the experiences of marginalized individuals who ride a bike infrequently in Portland, Oregon?

2. What are the barriers to cycling related to individuals' marginalized identities of gender, race, and class, and other relevant identities that may emerge?

I conceptualize marginalized cyclists as marginalized individuals, more specifically women and people of color (or racial/ethnic minorities), who ride a bike. For the purposes of this research, marginalized cyclist also implies the aforementioned description of an infrequent cyclist.

My findings show that gender and race inequalities are amplified in unique ways for marginalized and infrequent cyclists. However, the inequalities faced by participants in this study implicate a singular dilemma: a cycling culture that prefers an elite, masculine, and white cyclist, or, members of the hegemonic bike culture of Portland. Due to a hegemonic bike culture, existing gender and race inequalities are amplified and can be seen as a new form of spatial inequality for women and racial/ ethnic minority cyclists. 
In this chapter, I will focus on how cycling inequalities are perpetuated by the hegemonic bike culture, and in the next chapter I will focus on how the city is planned in favor of this dominant class of bikers. For women in this sample, spatial inequality will be illustrated through their duties of child rearing, their fear of harassment and visibility, and the way cycling spaces are oppressive to women through discrimination and domination. For cyclists of color, spatial inequality is seen through their experiences of racial profiling and discrimination, invisibility in cycling spaces and ads, and their isolation from other cyclists of color. Furthermore, intersecting identities shape the experiences of marginalized cyclists beyond gendered and racial dynamics: class and ability emerge as impactful for marginalized cyclists. The inequalities and identities discussed in this chapter cannot be understood as additive: they multiply to create unique oppressions and experiences for cyclists.

Description of the hegemonic bike culture: archetypes of an elite, white, masculine cyclist

To help illustrate the comparisons my participants would be making between themselves and other cyclists, I asked early in the interview: "How do you think your experience compares to the average Portland cyclist?” The answers to this question established commonalities of what my participants, as "infrequent" cyclists, were comparing themselves to; oftentimes, they described the average Portland cyclists as an avid or more skilled cyclist. This established early in the interviews that there were feeling of exclusion or inferiority for marginalized cyclists in the larger Portland context. The data demonstrate this relationship as gendered and racial. 
For several reasons, participants in this study felt excluded from the larger Portland bike culture or community. When asked what the average Portland cyclist looks like, most respondents envisioned someone different from themselves: a white man, often wearing spandex or cut-off shorts, and often competitive with an expensive bike or a single speed bike with accompanying hipster gear. There were slight variations in descriptions of their style, but the average Portland cyclist can be sorted into two groups. The first archetype was the hipster who rode a fixed-gear bike, wore cut off shorts, thick framed glasses, and tattoos, and drank coffee or kombucha. The other archetype was the sporty or avid cyclist, who spends a lot of money on their bike with many gears, has many lights, wears clipless pedals, but most importantly: wears spandex. Both the hipster and spandex archetypes are described as snobbish. Outside of these two archetypes, respondents of color sometimes mentioned that white women were among the average Portland cyclist too, but the consensus was always primarily white men. When class was mentioned, the men were always of a higher socioeconomic status. Most women in this sample expressed that they would like to make friends with more cyclists, or get their friends to bike with them, yet also indicating no interest or feeling of welcome in joining the already established bike culture. Both women participants and participants of color spoke of underrepresentation of cyclists like themselves in Portland and attributed feelings of exclusivity, or isolation, as barriers to biking.

Experiences of exclusion and isolation are indicative of the elite, white, and hegemonic masculine dominance of cycling space perpetuated by archetypes of an average Portland cyclist. Participants often described imagery of being passed speedily 
by these hipster and spandex cyclists, or they reported feeling inferior compared to the Portland cyclist archetypes in the frequency or vigor that they bike. Not only did participants report feeling intimidated or excluded by the white male cyclist archetypes, they often perceived aggression from these cyclists. In the way that white male cyclists physically move through space, they express masculine domination within shared cycling spaces. The idea of physical domination will be expanded on for both gendered spatial inequality and racial spatial inequality.

\section{GENDER INEQUALITY IN CYCLING SPACES}

\section{Child Rearing}

A common barrier to cycling among women in this study was the responsibilities associated with motherhood. Some participants in this study were parents to, or had previously parented, young children. In most cases, motherhood was a significant barrier to bicycling for these women. Despite their participation in this study indicating that they bike "infrequently," participants who were parents often had the most difficulty finding time to use their bicycle whether for utility or recreation. One white woman participant and mother to a grade schooler, Evelyn, reflected on losing her time to ride her bicycle after having her first child. She talked about having to use the family car to take care of their son, while her husband the father commuted to and from work by bicycle. She saw this transformation of her cycling habits as a feminist issue:

This is totally, I think, a feminist issue and why...women don't ride bikes as much. Because we are, very often, the ones who are responsible for childcare and child pick up and grocery shopping, which is more difficult to do for a family on a 
bike... when you start having those family responsibilities you don't have as many choices about transportation, when you're a privileged person such as myself.

In how Evelyn describes it, spatial inequality can mean the loss (even if just temporarily) of less encumbered movement, for a mother that is preoccupied with child rearing duties. For mothers, accessing cycling means first jumping through many hoops of transporting children and their needs on a bike. In this way gender inequality for mothers, and their expectations as the primary child caretaker in a family unit, translates to unequal access to mobilities and public space through cycling. Evelyn distinguishes her inability to bike freely as a feminist issue; her husband does not have the same obstacles to cycling despite his role as a parent.

Evelyn touches on another point of cycling access, and that is of her class: while Evelyn wishes that she could find more time to bike, she simultaneously calls out her privilege in having a car because she is able to choose the convenience of driving as a busy mother. Evelyn and her family have resources, such as a car, that lower socioeconomic status individuals may lack. In this way, Evelyn can choose to avoid certain aspects of spatial gender inequality that she may face as a woman by not subjecting herself to the vulnerability of placing her body on display while cycling and with her child in tow. Despite Evelyn's fewer choices of transport as a mother and a woman, she acknowledges that lower class individuals may have even fewer choices.

There are several points of privilege or marginalization that are related to a person's spatial inequality. Evelyn describes the physical difficulty child rearing creates for transport, but perhaps in a different world her husband would be able to assist more 
with child rearing duties. They might be able to invest in cycling gear intended to carry children in, or as Evelyn's child ages, she could have fewer places to go and more accessible places to bike to instead, assuming her husband contributes to the responsibilities of child rearing. Single parenthood, however, may bring even more unique challenges to mobility choices for mothers. Janet, a single white mother, assumes all responsibility for managing her and her child's time, without the help of a partner or spouse, and pointed out the physical difficulties and demands of child rearing that pose a problem to her bicycling:

I've commuted downtown almost every day in all of my 20 s... The fact of being a mother... and always having to schlep all that stuff around... it makes it not fun. And then being a mother, it's a timing thing. If it's past a certain time, I don't have time to ride my bike to work...I might have intentions, like 'I'm going to ride my bike tomorrow, and get everything ready,' and then the morning gets away from me.

Janet was one of the few women in this study who previously biked both for sport and as an avid commuter: she used to race bikes and spend her time with other cyclists from her racing community. Despite her child now being in his teens, she has not gained back her previous habits of avid cycling, but instead bikes infrequently and cites parenthood as a main barrier. For mothers, their propensity to bike does not rely on having young children, but being a part of a family unit might transform old hobbies or activities into infrequent ones. The transformation of lifestyle that comes with childrearing might be exacerbated depending on your family unit, especially as a single mother with less support and resources for the tasks of parenting. 
As displayed with Evelyn and Janet, being a parent dictates whether they can bike or not due to scheduling conflicts, extra tasks that come with parenting such as carrying more things (or as Janet coins it, "schlepping" children's stuff around), or having to revolve your schedule around childcare activities and taking a child on daily errands. All of the above challenges are easily solved by driving a car over riding a bike to carry children, child seats, groceries, and a myriad of other extracurricular items that come with parenthood. Often participants mentioned that some parents in Portland do bike with their children and even have child seat bike attachments; in all mentions of these individuals, participants praised those parents and assumed that carrying a child on a bike was a part of people's regular commuting routine to work or errands. Participants assumed that in some way, parents who rode tandem with their children had a sort of superior ability that allowed them to manage traveling by bike with child(ren). In reality, most parents who choose to ride their bikes in tandem with children will face the same encumbered barrier.

Another barrier associated with parenting, that encompasses both the issues of time management and the physical demand, is the matter of exhaustion that a parent faces which may differ from their pre-parenthood energy. This leaves parents with less energy, time, and resources for their own self-interests and reprioritizes daily parts of life such as exercise and recreation. Aneisha, a Black mother of two older children and busy education administrator, speaks to her experiences on exiting the young and dependent child-rearing phase of motherhood and is on the upswing of another parental transition; as her children approach adolescence, she is gaining back time, energy, and self-serving activities and has a new capacity to choose cycling as an exercise and hobby: 
What makes [cycling] positive is that I get some adult time, I realized how important that was. So and again, as the boys get older, I'm still doing a lot with them-a lot with them and for them, but taking an hour doesn't provide a whole lot of guilt. So, that's been nice, and I have [my husband]... I make sure they have all their needs- food and dinner. [He] comes home and I can let that go... the house isn't going to fall apart, so that was recent. That was very recent. But again, I was, you know, they're little, so you gotta make sure that the bath is done and the this is done and the that is done. And then put them in bed by eight, and I'm not going cycling past eight, so... it was all about family.

Aneisha's choice to take cycling up as a hobby completely emerged out of the new independence she has gained as her children, now eleven and twelve, mature and gain their own independence. As other mothers in this study indicated, their life, and choices, revolve around their roles as parents: cycling comes after their children. Aneisha's blossoming hobby of cycling should not be confused with commuter cycling as a necessity: Aneisha's class position enables her to financially invest in bikes for her and her family, as well as certain gear or clothing that many participants in this study voiced they could not afford. Her class also illustrates a privilege that comes with a well-paying job: taking care of her family and finding time outside of that task to enjoy physical activities and exercise, which many may not have time or energy for.

Parenting in general may act as a barrier to cycling, but the gender roles that apply to this sample of women, and their motherhood, specifically affect their access to cycling which reflects what spatial inequality means for motherhood. Evelyn illustrates this point not only in her "feminist issue" comment above, but also by describing how the "demands placed on" affect her transportation choices whereas her husband can commute to work and back by bike. She explicitly attributes the prohibition of identifying as a biker to her identity as a women and mother: 
But I do feel like being a woman affects my identify as a biker, just because I don't see it as an option for me as much anymore because of having to pick up kids from school, and having to be responsible for the grocery shopping, and always feeling like, you know, there's just not enough time to do any of that stuff. And especially if I'm going to take the time to ride my bike to do it, because it usually takes a little bit longer unless it's a really short trip... I oftentimes feel like I don't have that time, because of all the other demands that are placed on me.

Evelyn alludes to the fact that motherhood involves expectations and limitations based on societal gender roles that dictate women's child-rearing duties, including the labor of child care, transporting children, and other primary child-rearing activities such as cooking, shopping, and cleaning up after children. The gendered norms of motherhood interfere with the choice to bike; thus, for Evelyn, gender inequality is tied to her spatial inequality. These findings echo earlier research on women's confinement to the private spheres such as the household and away from cities. Women's unpaid and paid work shapes their spatial relations (Preston and Ustundag 2005). Women's role, and unpaid labor, as caretaker to their children encumbers their movement and agency in accessing public spaces. The restriction of women's mobilities reinforce masculine public spheres such as the city and its cycling spaces.

In this section I discussed the roles and expectations specific to motherhood and child rearing that create a gendered barrier to biking. I also address how gender and class intersect to create unique identities for these marginalized cyclists, as well as unique advantages and disadvantages in their access to cycling. The mothers in this sample are financially able to choose driving as a mode of transport over biking. No mothers in this sample chose to transport themselves along with their children by bike, but as one can 
imagine, purchasing a bike can be more affordable than a car making it a more feasible or even necessary option for some economically disadvantaged individuals.

\section{Fear of Harassment and Visibility}

As Valentine theorizes, women experience a "geography of fear" that impacts how they access public spaces and what mobilities they choose (1989). From the stance of marginalized cyclists, the same anxieties and fears transfer to cycling spaces due to the domination of cycling spaces by men. Women are aware of potential scrutiny or harassment they face in all kinds of spaces; cycling spaces such as bike lanes, roads, parks, or bike shops are not exempt.

Women attribute their visibility or invisibility on bikes to perpetuating a geography of fear. Similar to Steinbach et al.'s (2011) findings, women from this sample felt simultaneously visible and invisible on their bikes. Visibility emerged as both a positive and a negative aspect of women's experiences. Women often reported that they felt agency with the speed that a bike provides for escaping perceived (or actual) threats versus walking. Some women felt empowered by the freedom they experienced on their bikes. At the same time, women's visibility was associated with feelings of anxiety and fear about being alone, vulnerable, or exposed on a bike. Participants related their cautious feelings towards cycling to the larger risks associated with moving as a woman in a public space; sometimes empowerment was attributed to braving their feelings of vulnerability. Aside from the positive feelings of visibility felt by women in this sample, I will display how the negative aspects of visibility reflect a gendered spatial inequality. The masculine dominance of public space is enforced by the perception of threat that 
women feel on a bike, as well as the scrutiny they face by mobilizing their bodies while biking.

Women experience spatial inequality in that they feel that they must attend to these extra safety concerns in order to be able to accessing the same cycling spaces that white men are freely and unthinkingly able to utilize. Many women in this sample shared that they restrict their movement while biking based on location and time of day. Carol, a Latina woman, used the metaphor of a "lady's map" to highlight what most women participants felt about avoiding cycling in certain areas:

I think on a bicycle I would be a little bit more cautious. I would go to bars maybe [in] the central eastside, but I wouldn't want to come downtown because stuff can get kind of sketchy... I think bicycling at night I'd have to turn on that female sense of like, there's a map of the city and then there's a lady's map of the city which is like you shouldn't go there, you shouldn't go there at night. And maybe why I choose to drive is because it's being able to say I don't have to pay attention to that. I can go where I want.

The "lady's map of the city" that Carol refers to illustrates an aspect of spatial inequality that women face in their cycling. As Valentine explains, women have a geography of fear (1989) which can be extended to cycling spaces; women have access to public space, bike lanes, and bike paths, but there is a secondary question of where they should be going despite having the agency to choose where they ride. In this way, women are constantly aware of potential threats from masculine spatial dominance. Women cyclists carry a second consciousness regarding their cycling mobility: like men, women have literal access to cycling spaces, but their fear controls their choice in accessing it. Thus, the geography of fear held by women reflects their unequal safety, as they are constantly aware of potential threats from masculine actors who dominated the shared spaces. 
Gendered spatial inequality is evidenced by the way women are restricted in their mobility. For Carol, the potential of threat bars her from riding her bike to specific areas in town. Women may want to ride to certain areas, and to choose cycling over other means of transportation, but the area that they are moving through dictates whether they should be biking there. Oftentimes, this results in women either avoiding neighborhoods or areas completely, as well as certain times of day such as after nightfall. Unfortunately, this can result in women choosing to drive because they must choose safety over the healthy and environmentally friendly, yet vulnerable, choice of biking.

In addition to women worrying about where they ride their bikes, the women in this study acknowledged that clothing choices matters for their visibility and feelings of security. Because of women's subordinated position in society, they are subjected to scrutiny in how they move through space, including what appearance they upkeep, such as clothing choices. Velia, a Latina woman, indicated that she has been harassed while riding her bike based on what she is wearing:

I wear wherever I want when I'm riding a bike. But that also comes with like people looking at you or making comments because it's hot and I'm wearing short shorts and I'm riding a bike. Or I'm wearing a tank top and I'm on a bike. I'm more of visible because I am a woman on a bike.

For Velia, wearing comfortable clothes on a bike means taking a risk that you will receive unwanted attention for being visible. Even though she is engaging in physical activity, and in already hot temperature conditions in the above scenario, Velia expresses that she is scrutinized for a choice that she perceives as reasonable. As many women expressed similar feelings of scrutiny for what they wear while biking, we can see where 
the gendered order for women is perpetuated on a bike: how you choose to cover your body merits others to gaze and judge it, regardless of using your body for physical exertion. As I will discuss later, some women in this sample faced explicit sexual harassment on their bikes.

Whether they have experienced harassment or not, women have to be conscious and aware of what they are wearing while they bike despite the athletic nature of biking. The range of motion and distances that come with riding a bike should allow for individuals to feel more entitled to wearing less, cooler, or more comfortable, clothing than they would walking or driving through public space. What women choose to wear also relates to gendered spatial inequality: as women determine a cost-benefit analysis of wearing comfortable clothes in public, they will apply their situation to their consciousness of the geography of fear. In an urban setting such as Portland, this scrutiny is amplified when moving through populous areas. Applied here, the geography of fear indicates how women will be aware of their dress based on precursory fears of the male gaze and potential harassment. Women's feelings of visibility determine whether they can feel safe and comfortable while exposing their bodies (scantily clad or not) as they are moving through certain neighborhoods or areas. This consciousness might discourage women from choosing to bike, or biking in certain areas. Based on the energy or anxiety that culminate from multiple strands of hyperawareness for women, women feel required to decide what to wear and where to go on their bikes.

The fears of harassment held by many women in this sample had been realized for some of my participants. A few women responded to questions about their feelings of 
safety and negative experiences on a bike by discussing specific examples of harassment. Many participating women were catcalled or yelled at, blockaded by men on sidewalks, or recounted stories of other women-identifying friends who had been assaulted while riding their bike. Many instances involved women being vulnerable on their bikes riding next to men in cars. Margaret, a white woman, recounted one of the more vivid and dangerous scenarios of harassment, which could have resulted in an injury or accident:

One particular time, and this has happened many times, but this was one where I actually felt a little bit scared, like I might get run off of the road... a friend and I were riding up North Denver Avenue and these guys passed us once, I think, and then we came up to a stoplight, and then they started revving up again and they passed us again. And as they passed, they were like "I wanna grab your ass! I wanna grab your ass!" and they were leaning out of the window as we were biking up Denver right as [the road] starts getting really narrow there... And I was like, oh my god, I'm going to get smashed into the parked cars over here.

Margaret's experience is indicative of the way that masculinity reigns over public space and originates women's fear and spatial inequality. Even when women are with other women or without men in a bike lane, they are still subjected to the whim of heteronormative and sexually aggressive social norms.

Although Margaret was one of the only women in this sample to discuss such a dangerous and horrific example of harassment on her bike, it is clear that women are controlled by the fear of instances such as this; their restrained choice of mobility reflects spatial inequality. Tara, a Native American woman, speaks to the same controlling fear as something that keeps her from biking at night. She reflects on an instance where she was out at night near a park, walking her bike, when she was alone and intimidated by unknown men: 
Oh yeah, that's why I don't like to at night, other than not being super visible... One time I was walking by Laurelhurst Park on my bike, and this homeless guy jumped out and he just got really close to me and just stood there. So I was like, "OK..." and you know, went around him. And his friend jumped out. And I was like, "Uhhh..." so I backed up to the street, and there were cars coming, and I just got in the middle of the street so that they had to stop. And then I pointed at the guys, and they were honking at the guys, you know? Because I just wanted to get somebody's attention... I don't know what they were going to try, to jump me, or something? I have no idea, but I didn't want to find out. So, it is scary being a woman.

Tara attributes her frightening situation to her gender identity; being a woman at night automatically translates to fear. Women are controlled by the perception of threat that leads them to fear they may encounter a dangerous or violent situation in public spaces. Despite any other identities or circumstances that could have been at play for Tara being at risk (such as being in a neighborhood with a high crime rate), she affirms that by being exposed to the urban landscape at night, she is exposed to more danger as a woman.

These findings support other studies showing that women feel vulnerable on their bikes and worry about street harassment and crime. Normally, cyclists have to be cautious of traffic, cars, and conflicts of motorists: women have these worries in combination with their bodies being subjected to the gendered order and spatial inequality. The order of the power and domination of men over women is amplified in public spaces such as roads, bike lanes, and parks. Despite the agency that some women may feel while riding a bike, a patriarchal ordering of public spaces is perpetuated by both the fear and consciousness of risk that women carry with them, as well as previous negative experiences with harassment. Through the way that gender inequality is perpetuated through public space, one can see how women's mobility choices are shaped 
by the larger spatial inequality. Women in this sample worried about what they wore, where they went on their bikes, and how they would be treated by men in and out of cars. Gendered Spaces (Bike lane domination, bike shops, and men's representation)

Also indicative of the hegemonic bike culture, women generally felt isolated while biking and that they had no personal connections with or representation in the larger cycling community of Portland. The gendering of spaces in favor of men leads to feelings of exclusivity, and actors in those spaces behave in ways that perpetuate the gendered order. Many women in this study felt unusual as a woman cyclist, and often did not know many women who biked in their personal lives. When they bike in the streets of Portland, they mostly ride along the previously mentioned white male archetypes. Tara, a Native American woman, likens her experience biking as a woman to the experience of a minority: "Bicycling as a woman, being the minority, I feel like that's the same as in life: I'm a minority. I think it shapes my experience... it just feels like everything else in the world to me." Tara also discusses the isolation she feels as a woman cyclist compared to her circle of friends who do not bike. Yet Tara is able to rationalize women's biking behavior as normal when she sees other women cyclists. When asked why she likes seeing other women biking, Tara said:

Because I don't feel alone, I don't feel weird, because all of my friends are girls that I grew up with, and now they all work in offices, and wear high heels, they're really pretty and they do their hair and make-up and stuff. You know, stuff that I don't really do too much of. They would never ride bikes, ever; so I feel really weird riding a bike. When I see other women bikers, I don't feel that weird. Like maybe I need to make friends with them.

Tara, like many other women in this study, highlights a crucial piece that women feel they are missing: a community of women cyclists. As a follow-up to each woman who 
cited issues of this gendered isolation, I asked if seeing more women cycling in Portland would increase their cycling rates: all said that seeing more women cyclists, or having other women to bike with, would actively encourage them to bike more.

Although the women in this sample could pinpoint specific feelings of exclusion or isolation, there was also a general "clique" that they did not feel they could break into. Despite the lack of clarity with what form or shape the clique takes without representative data, it is worth noting that the cycling clique is noticed and felt by the entirety of this sample. This more nuanced, yet specific, feeling of exclusion could act as a barrier to many cyclists, or potential cyclists, outside of this sample. Angela puts it best by describing the "in-crowd" that she has not accessed, nor wants to:

I feel like I'm not part of the in-crowd yet, and I don't know if I want to be. There's definitely a bicycle clique... [I can tell you] the demographic of people in the clique, perhaps, but it seems like upwardly mobile white people that wear a lot of bright spandex and are very, very into what they do, and are very skinny and have beautifully muscular legs, but are intimidating. [Chuckles] And I think it's even close to here, but there's this bar-bicycle club and I was like, oh my gosh, people take their bicycles to hang out at a bar, I had no idea.

In the sense that Angela described the clique, it is new, overwhelming, and larger than her idea of cycling. Angela does not see cycling as something you go to a bar to engage with. This general sense of a clique was described by many participants who had the general sense that bicycling in Portland was "cooler" or "better" than what they were willing or capable of doing. Some participants noticed this, but were very critical of members of the clique, as cycling is a means of transportation, not a subculture, to them. However, when the "clique" is larger than the population of women cyclists, women are 
impacted by the masculine domination of shared city spaces, not excluding the bike lanes.

Oftentimes, women in this sample felt deterred by the cyclists who surrounded them while physically riding due impressions of inferiority or unwanted competition from male cyclists. Physicality ranged widely among this sample of women, but most recognized that the bike lanes were dominated by competitive, and presumably athletic, riders. As mentioned previously, most women conceptualized the average Portland cyclist as a white male. Adding the additional layer of competitiveness or aggression to a white male serves to further alienate women from the bike community if they are biking as a means of transportation or for recreation, not for sport, speed, or competition. Being surrounded by this type of cyclist contributed to the feeling of exclusion that Robin, an African American woman, felt while riding:

The feeling on that route is not inclusive. It's not we're all out to sort of watch out for each other. It's really competitive. It feels like a freaking, you know, that bike race in Tour de France. And you know, for me, I'm fifty-five years old. I just want to get home. I'm not racing anybody... Sometimes when dealing with those speedy cyclists, I think that it's possible that I'm not as respected as much as some other...some guy in Spandex or some other thing. They just see me on this kind of frumpy looking bike.

Robin's sentiment of not wanting to "race" others on her bike was felt by many participants, even women who stated that they enjoyed biking for physical exercise. Robin further explains how she feels that her route is dominated by aggression when riding with speedy cyclists, who she previously identified as the previously mentioned white spandex cyclist archetype. Her labeling of the white cyclist demographic as 'white spandex guys' was felt by the majority of participants. The expectation of the white 
spandex guy being the ideal rider might perpetuate spatial inequality for cyclists, seeing as they are not represented and feel uncomfortable riding. They often feel aggression directed towards them by male cyclists, and isolated due to their gender in a maledominated activity. A sense of community, and having fellow women to ride with, would motivate these women to ride their bikes more.

Moreover, women specifically felt excluded from Portland's bike culture due to gendered acts of discrimination by men in the cycling community. Women were affected by the patriarchal order not only while riding their bikes, but out of the bike lanes as well. Often discrimination was difficult to pinpoint for women reflecting on their experiences while riding a bike; they described those instances as obvious aggression but without the clarity of differential treatment. However, clarity was provided when women were discriminated against in bike shops. Nicole, a 26-year-old white woman, explained her frustration over the discrimination she receives from the men who staff her local bike shop, unlike her husband:

I have taken my bike in to get serviced a couple of times. And it's kind of like taking your car to a mechanic where the person who is explaining what's wrong doesn't explain in as technical of terms or as detailed to me. But if I bring my husband along it gets all sorts of detail. And it's funny because my husband knows that like how I feel about different things like that, and that I'm more than capable of getting in there, getting dirty, fixing things. Like I'm the one that fixes things in our house.

Nicole recognizes the difference in treatment between her and her husband based on gender, and that she may be abnormal among women for fixing things in her household. Like Nicole, many women in this sample reflected upon instances where they were patronized or snubbed by bike shop employees or mechanics. With or without their own 
mechanical knowledge, they recognized when they were being discriminated against. Although patronizing behaviors can offer slight amusement for those women who were treated delicately or insincerely, like Nicole, women could still cite these masculine behaviors as airs of superiority. Other women suggested that they might be treated with more kindness based on their gender (women "needing more help," than men) but that there was still a difference in how they were treated compared to male customers. Often when women in this sample were asked if there were any positive aspects of being a woman cyclist versus a male cyclist, they could only come up with this potential boost in kindness or preferential treatment by males in cycling spaces. When men treat women differently or discriminate against them when women attempt to access cycling resources, they send a message that women do not belong in those spaces. Indeed, not only can women cyclists in Portland not enter cycling spaces without facing various barriers and forms of spatial inequality, they cannot patronize cycling shops without facing discrimination.

\section{Positive Visibility: Empowerment and Agency}

Despite many gendered barriers and facets of inequality faced by women cyclists, some participants were able to find positivity in their visibility on a bike. One positive aspect of being visible on a bike is the speed and agency biking can provide for otherwise vulnerable, still, or slower women bodies. Rosa, a Latina woman, indicated that she enjoys the agency of biking when it comes to avoiding unwelcome advances:

...I feel like I'm less available for people to talk to me. All of my weird experiences have been waiting for the bus or being on the bus. And suddenly this seventy-year old man wants me to be his girlfriend. I swear to God. This just happened this week, where he's like, I am picturing like the two of us in those two 
seats at the movies. And I just sandwich myself in between two people as soon as possible. And that never happens on a bike, you know, because they literally can't talk to you because you are moving. So that's actually something I've liked more, I think.

The ability to escape unwanted advances and to move freely through space is empowering to Rosa. Carla, a Black woman, echoes Rosa's sentiments of agency with feelings of freedom through biking, granting her empowerment:

I would say bikes actually give me more freedom. Some of that might be fake freedom, because it's not like some car couldn't hit you ... but I do feel like if you're worried at night...worried [about] walking the pace you're walking, or running away from somebody- [that] fear that most women carry around by being out late at night- I just feel a lot safer... as long as I'm moving on my bike it'd be really hard for somebody to attack me. Even if I was at a stoplight late at night, I could just go ahead and run it if I really felt that way, so I would probably say, I feel like it gives me more freedom to move than I would if I were walking.

The geography of fear dictates that women be cautious in where they place themselves, which routes they take, and what mode of transportation they use. However, cycling can grant agency over walking or standing still for women by offering speed and freedom of mobility. Despite the vulnerability associated with being on a bike, women can bike faster than they can walk or run. As Rosa demonstrates, oftentimes women are vulnerable when they are waiting, standing on the street, or sitting on public transportation; in the cases where these mobilities are necessary, women have no choice or say in how quickly they move besides the potential of running. Women are sometimes subjected to interaction in the streets that they can avoid by pedaling quickly away. This means that cycling, although controlled by a gendered order, has the potential to improve women's mobilities. 
As noted with Rosa and Carla, visibility can translate into positive empowerment for the speed and agency that riding a bike can provide. Another form of empowerment found through cycling is simply putting your body in display despite any adversity women may feel. Julia, a white genderqueer/femme, often spoke about her struggles with being an overweight cyclist, yet found empowerment in biking as a feminine body combined with what she called her fat identity:

I hate to make everything about fat... but my body is key to my gender identity too. So, and in fact that confluence of size that is disdained by larger society with an expression of gender in a way... there is something about being willing to get on a bike in my body, in my gender, that is a cool thing... there's just something about being visible, because you're really visible on a bike in a way that you're not in a car say, right? And so there's something about that visibility that I think is pretty cool.

Julia cited many times that she has been stared at, treated with disdain, or just felt that she stood out while on her bike due to her being a fat and feminine presenting person. Even though often times these feelings were difficult for her, especially when coupled with a physical difficulty due to disability that also causes difficulty cycling up hills, Julia saw the bravery in herself that she had hoped that onlookers of her cycling might see. Because cycling might be more difficult for Julia than an able-bodied, fit, or thin person, she is proud to bike by recognizing the lower odds of a fat or disabled person biking in combination with feelings of gender empowerment by presenting as feminine on a bike. She is also able to appreciate the intersection of gender embodiment with her size and ability and celebrates her gender through her ability to bike at all through public space.

The intersection of gender expression and embodiment need not be specific to ability or physicality as it is for Julia. Overall, many women cited feelings of freedom 
and empowerment when describing the positive aspects of bike riding. Some women attributed this empowerment to speed, others felt strength and power being a woman on a bike. There are implications in these findings that biking might be perceived, whether subconsciously or by societal attitudes, as a brave or masculine activity. Perhaps a woman accessing cycling in her feminine body will defy the standard of who is expected to move quickly, be athletic, be outside of a car, or just who can ride a bike.

Despite the barriers to bicycling that women report, this research identifies a positive trait to the visibility of women cyclists: empowerment. As women are able to move through their public space with more power and speed on a bike, many felt strengthened against potential threats. Feelings of empowerment have the potential to change feminine attributes into a new stimulation for women-identifying cyclists. Velia, who noted the scrutiny she receives while wearing short-shorts on her bike, still expressed that she wears what she wants. Velia's choice has the potential to empower other women to dressing comfortably rather than allowing the gaze of spectators to dictate what you wear on a bike. Julia, despite feeling uncomfortable by onlookers, enjoys riding her bike as a fat femme in that it makes a statement about her gender expression and body as it relates to bravery and strength. Although women must reconcile the perception of threat and anxieties with their movement through public space, what they wear, and who they could encounter, gender expression still holds the potential to positively impact women's cycling. 


\section{RACIAL INEQUALITY IN CYCLING SPACES}

\section{Racialized fear of public spaces}

The fear of public spaces extends beyond gender inequality, and according to people of color in my sample, is often racialized. Several women of color from this sample cited race as an overarching oppressive identity, in combination with their gender, and would often suggest that their experiences on a bike mirrored larger systemic inequalities that they, and other racial minorities, faced every day. Janae felt most unsafe riding her bike due to racial profiling over other compounding issues of gender. Not only was she discriminated against and harassed, she also had many encounters with racism and racial slurs. She spoke of her African American identity as pervasively affecting her life, and how these layers of oppression affect her biking experience:

I feel that being African American, I am more hyper vigilant. I am more fearful than a typical Caucasian person could be on the same bike, in the same neighborhood, at the same time. I have these layers of oppression, if you will, to have to worry about that never crosses a Caucasian person's mind. Privilege is one of them- they have the privilege, I mean, Caucasian culture has the privilege of being able to ride a bike, any time of day, at any hour, in any neighborhood, and can feel relatively safe. Unlike myself, you know, I'm thinking I am aware of my color, and of my culture, and my being an African American woman at all times. I have to be aware of my surroundings. And it's, man, having all of these awarenesses and it does interrupt my experience. I can't really enjoy my experience as much as a typical person would because of all of the oppression that comes with riding a bike as an African American in our community.

Janae brings to light an important issue to Portland and this research: racism towards the

African American population. Janae also brought forth the example of "driving while black" in our interview; she understands "cycling while black" as a similar phenomenon.

Not only do women of color like Janae have to worry about being targeted for their feminine expression in public spaces, they also worry about racial discrimination, 
profiling, and targeting. Janae went on to explain times that she has had the cops called on her, or been stopped by the cops, while riding her bike or walking in Portland. At times, she would prefer to drive her car to avoid this scrutiny and trauma altogether.

Marcus, one of the few African American men in this sample, cited a unique kind of discrimination with the racial tension that he feels in Portland. Marcus mentioned early on in our interview that there have been times in the past where he will avoid biking as he feels unsafe due to the low African American representation in Portland combined with anxiety related to nationwide violence, more specifically, shootings of African American men. He explains how racism and racial tension in Portland translate to everyday cycling:

And honestly, I feel... I do feel like being a minority in Portland, like I've noticed that motorists are less likely to stop for you...if you're at like a crosswalk, even if you have the right away. Which I do. I always have the right away if you're a cyclists or you're a pedestrian. But it seems like...And the reason I say that is because like I've been at a stop before and just waiting for people to stop. And then like someone... [chuckles] You know, a white person will pull up next to me. And then all of a sudden, you know, traffic stops.

Men of color like Marcus are faced with exclusivity of bike culture, and there are further intersectional and gendered implications of black men cycling in Portland. Thus, men of color might be subjected to unique forms of discrimination that are they are not immune from on a bike. Janae recites some of these concerns, but Marcus echoes his unique situation concisely: a man of color is subjected to more dangerous racial targeting and profiling than others. Racism in cycling spaces goes beyond micro aggressions with other cyclists, pedestrians, and motorists. For people of color in Portland, they are attuned to dangerous racial profiling that white people are protected from by their privilege. Racial profiling and shooting of African Americans arose as a barrier for Black 
participants in this sample. Like with "driving while Black", some participants indicated that they are stopped on their bicycles by police. For African American participants, their subjugation to racial profiling permeates in all mobility and transportation choices. Despite any optimism I might have had when asking Black participants about their positive cycling experiences, including feelings of freedom cited by most participants, Black cyclists from my sample could not separate significant issues of racism from their access to cycling spaces. Awareness of safety issues for Blacks goes beyond their day-today feelings, experiences, or expectations: racism against African Americans is a national issue, and daily acts of violence, hate crimes, and racism can result in daily fear in Portland.

When I interviewed Marcus in the Fall of 2016, he spoke to the aftermath of the increasing number of police shootings of African Americans nationwide. The Portland area had not had any recent police shootings specifically on African Americans, but it did not mean that African Americans were granted immunity to racialized fear of police violence. For Marcus, this fear altered his cycling choices. When I asked Marcus about feeling of safety, I meant overall, but he cited being fairly fearless besides the potential for police violence:

Interviewer: When do you not feel safe?

Marcus: I think I don't feel safe if it were something crazy happens in the news that like elevates racial tension. That's when I feel like the least safe, you know. Interviewer: Does it stop you from biking?

Marcus: It did, yeah. The recent shootings, I stopped for awhile. Yeah. Interviewer: What made you go back to biking? 
Marcus: I think once everything had kind of calmed down and people focused their attention on other things, you know. Then I felt okay, I guess.

When Janae was asked the same question during our interview, her response echoed the specific fear of police as an African American:

Yeah, yeah, police, and feeling scared. Feeling scared for my life at all times, the way that they've been killing African Americans. And I think that is one huge deterrent of why African Americans in this community do not ride bikes. We try to lessen the risk of having any interaction with the police, period, point blank.

Despite the few data from this study displaying a fear of police, Black police violence is a nationwide crisis with significant consequences on African Americans and should be considered a barrier to cycling for people of color. In 2016 alone, police shot and killed 308 African Americans, and are three times more likely to be killed by police than whites (MappingPoliceViolence.org). Marcus' experiences support studies that show how Black men's mobility patterns are altered by 'gunscapes', or police presence and fear of being pulled over while driving (Nicholson 2016). More efforts should be made to understanding how police violence negatively affects mobility choices for people of color, especially during times of high tension for African Americans. Spatial inequality for marginalized cyclists is further racialized by fears specific to Black populations. Given the vulnerable nature and visibility that comes with cycling, fears that Black men carry with them in public spaces might be amplified for Black bodies on bikes. Much like the gendered geography of fear, people of color harbor their own perceptions of risk based on evidence of a national racist climate.

Just as men of color might have unique fears while cycling, women of color face unique forms of oppression due to the intersection of feminine and nonwhite status. 
Feelings of anxiety as a woman cyclist compound with feelings of standing out in a masculinized activity. On top of gender inequality, minority or racial status amplifies these experiences. Women of color in this sample consistently reported that they felt highly visible among many white people in Portland. Moreover, the hyper visibility experienced by women of color is attributed to racism by white people. Helen, a Black woman who resides in North Portland, spoke of the importance of welcoming yourself to a space whether or not you actually feel welcome. Along with her courage, she faced some struggles with the feeling that her and her friends' Blackness was on display in public space:

If I am very honest, there's a small part of me that underneath, doesn't want to be a spectacle either. I want it to be normal. I don't want it to be a thing, that there's a big group of Black girls out on a bike. And some of them are super-curvy and not like lean typical looking bikers. Like, I don't want to be a thing out on the street. I want to just go hang out with my friends and bike... somebody was saying to me the other day, like welcome or not, welcome ourselves. You welcome yourself to a space. Everybody else can deal with it and get in line...or go somewhere else. That's so true. [But] I would be being less than completely transparent if I didn't also admit that there's like that hair in the back of my mind that also has that thought. Whether or not you accommodate it, that's on us... I don't want to be out with anybody that I care about and have anybody look at us or them being...with any kind of judgment. Like, "their body is not right for that," or, "wow, that's something you don't see," or, "look at that." Straight up. Like...I'm not here for anybody else. So that definitely. And again, there's safety in numbers. They're all doing it. I do it. And then you are with each other. And you're with yourself. And it doesn't matter what's going on in the world around you or if the world has a perception or not.

Helen's feelings reflect what other women in this sample felt: that they just wanted to be invisible, or left alone and without judgement. These feelings are exemplified when people of color put their nonwhite bodies on display in public spaces and are not only subjected to the male gaze, but the gaze of white individuals in a predominantly white 
city. There are multiple intersections of identities at play that Helen refers to when speaking of Black women as a spectacle. First, Black individuals face their own unique set of racial barriers and racist encounters that may be amplified further when habituating in a predominantly white city such as Portland. Second, Black women's physicality and body type can be subjected to additional scrutiny due to racist controlling images (Collins, 2000), which Helen raises as a possibility for curvier Black women. Being a Black woman cycling in a public space that is occupied primarily by white men (and sometimes white women) adds an additional layer of feeling abnormal on display, or as Helen puts it: being a spectacle. This contributes further to a theory of spatial inequality in that Black women, just by existing in public spaces, are potentially subjected to another consciousness or fear of standing out, or being hyper visible. In this example, Black women, unlike white men and white women, cannot walk or bike through white dominated space without being aware that they lack the privilege to go unnoticed. POC's invisibility and underrepresentation in images and spaces

For women of color, the intervention of increasing person of color representation is crucial. White women often cited that they had friends they knew who biked, and at least had some connection to other cyclists. Most of the time, women of color had no friends that ride a bike; Tara demonstrated her feelings of isolation in the gender section above by discussing how she is the only one among her group of friends that rides a bike. Women often felt that their lack of community was a primary barrier to biking. Ana explains what is felt by most women of color in this sample:

In my experience, and I don't know if this is because I'm a person of color, I feel like the typical bike cyclist is white people, men and women. I feel like I see a lot 
of female cyclists. I'm sure that there are more men. But from my experience, I feel like it's very much white men and women. So the question was how does my experience compare? I mean, it's definitely different in the sense that I don't see people like me, ever on bikes. It's very rare. I feel like I could count on one hand like my close friends of color who bike... I think a lot of parts of bike culture are definitely intimidating... When you go into any bike store, it's generally white men. Community Cycling Center is the closest...CCC is the closest bike shop to us. And there actually is some diversity there. Like I know there's a female mechanic. And I know there's a person of color - I'm not sure his background mechanic. So at least there's those two. But generally, you're not going to see people of color at CCC. So I think like in terms of the experience, there's definitely like you don't see yourself often. So it's a little bit like you don't really have that... people of color bike community.

As Ana displays, people of color are acutely aware of the lack of community and diversity in Portland. Even in an organization such as Community Cycling Center, which focuses on making biking accessible to people, Ana describes it as a space where people of color are largely invisible. Even with initiatives to overcome class barriers made by organizations like the $\mathrm{CCC}$, people of color may be left in marginalized positions that impact their use of cycling services. Most women of color in this sample shared the same concern of lacking a person of color bike community in Portland. With less community and a lack of representation, many unique experiences arise for people of color, men and women both, in the context of cycling in Portland.

Samuel, a Latino man who grew up in a culturally rich Latino community in California, discusses the surprise he gets from white Portlanders when they see him with his bike. Upon his arrival in Portland, Samuel himself was surprised to see the invisibility of the Latino and people of color communities. He voiced frustration that the representation of cyclists of color is further diminished by the images, advertisement, and 
commodification of cycling, which he finds specifically targeted towards upper class individuals:

Seeing biking as a white thing, you'll see these ads: "Go Green. Bike to work." White person on the ad. Alright. Again, erasing all those people, who have been biking, of color. All of a sudden it's this new thing? No. Bikes have been, back for centuries, so to make it a new thing by being green then... has that Black person on a bike, have they not been green then? I don't know. Things like that and it just makes me extrapolate and internalize it more... I just want to get to where I need to safe and in one piece. Things like that, little stupid micro aggressions. It's either you get to work in a car or public transportation- and you do see some Mexicans on bikes but it's really not that often and it's like, "Oh, you ride a bike? Ha ha ha." Yeah I ride a fucking bike, it's cheap man, I'm trying to be economical here! Gosh. Things like that.

Samuel voiced the comments he receives from white people, who act shocked that he rides a bike as a Latino person. Not only does Samuel miss out on a community of men and people of color to ride with, he feels scrutinized for simply biking in front of white people. This point is like Helen feeling like a spectacle for white people while riding with her Black friends: people of color are hyper visible on their bikes as they are not expected to be seen cycling. At the same time, Samuel feels his and other cyclists of color's experiences are diminished by white images throughout Portland. Furthermore, Samuel illustrates that he needs to defend his choice of transportation which is not exactly a choice he has made willingly. Samuel bikes to save money, and feels that his class status is scrutinized as well as his race by the white and potentially affluent people around him. In this way, his experience is shaped by his intersecting identities of race and class. Positive Cycling: Empowering and Connecting Cyclists of Colors Like with women in the above section, people of color identified positives of cycling. Overall, cyclists of color voiced desires to see diverse representation, and 
cyclists like themselves, in Portland bike spaces. The priorities of safety and comfort for marginalized cyclists overlap in terms of safety and comfort, but cyclists of color feel especially empowered by seeing cyclists like themselves. When asked about their ideal cycling experience or what would improve cycling conditions in Portland, cyclists of color tapped into the desire for a community that represents them. Janae describes a diverse community of cyclists as a top priority for her ideal cycling needs, along with benefits of a larger scope such as health and environmental impacts:

Janae: The health property and health benefits [of cycling], you know you're building that cardiovascular, and getting that workout in, weight loss, things like that. So that's the health benefits of it that I'm really appreciative [of]. And then riding, when I do get to ride with my friends, it's bonding time, it's quality time, that's what I really look forward to. You know, we have hectic schedules so when we come together it's really, really nice. And we're doing something positive, and we're doing something environmentally supportive so that's the deal. My ideal cycling situation is where there is a diverse group of people and they are just biking for a good cause. Now, that's an ideal situation.

Janae's words display the empowerment that cycling with peers can bring to marginalized cyclists. When working towards a mutual cause such as health improvement or climate action, Janae feels it's a triple victory if she can include her friends. For someone like Janae who experiences racial profiling on her bike, riding with friends can make a large impact on her habits. Spatial inequality for cyclists of color can be combatted with the power of numbers. Velia, a Latina participant, had previously lived and biked in Oakland, and feels negatively about the bike community in Portland due to its exclusive and white nature. She spoke fondly of her cycling community in Oakland, and in comparison, felt alienated and isolated as a woman of color in Portland. Her former cycling community consisted of diverse riders with a cohesive community: 
I was part of a community that did party rides. We would have a bike party every month... and we would do urban routes. And it would be like hundreds of people coming together to do a ride... so it was really cool. And going through neighborhoods that didn't have a lot of cycling in them... West Oakland has a lot of crime. But we would ride through West Oakland, just like as part of bike advocacy and encouraging people to ride their bikes... One of my best memories of riding, where we went on this ride. And I felt super supported, like both material and skill. Like if I got a flat, somebody was...I knew somebody would hang back with me and like help me. I'm like getting a little teary-eyed thinking about it. Just like the emotional support of doing something really hard and challenging, and like having somebody... give me pointers. It's like, you can do it. It was the best thing to just like have -a community that...that you shared this love of biking. And they were willing to support their friends in doing these like big, long challenging rides which I think is true bicycle advocacy. And there wasn't that pressure or bad kind of judgment of like what you show up in. Because some people show up in Spandex. And like some people would show up in regular clothes... there wasn't that pressure to like have the newest tag or have like be totally geared up or like have a super awesome bike or whatever. And everyone just kind of like pulled together.

Velia pinpoints what is wrong with the hegemonic bike culture in Portland by comparing it to Oakland's. Not only are there elements of support and representation of cyclists in her positive memories, but she touches on some classist and ableist issues that are associated with the elite, white, masculine cyclist of Portland. One's ability, athleticism, gear, spandex, or bike that you have should not matter for a cycling community, and yet it does in the experience of marginalized cyclists.

Like I described in the gender section, the same sense of visibility that both oppresses and empowers women extends to the experiences of cyclists of color. By having a diverse community, one that represents themselves and does not over represent a white population, cyclists of color feel empowered and inspired to ride their bikes. These data show that the processes of oppression for people of color can be rectified by social supports to improve cycling conditions. Systemic racism and the safety issues that entail 
interfere with safe access to cycling, and should be targeted for change to improve ridership for cyclists of color. If Portland can achieve safe ridership for all cyclists, more cyclists of color are likely to show up and hopefully the numbers snowball from there.

In this chapter, I demonstrated how inequalities shape cycling spaces. For women, gender inequality permeates in cycling by barriers of childrearing, fear of crime or violence, harassment, and underrepresentation. People of color are impacted by fear of profiling or violence and isolation. All of these inequalities are perpetuated by the bike culture which privileges an elite, white man, which participants conceptualized as the fit and multitudinous hipster or spandex cyclists. Fred Armisen's Portlandia character might be a stereotype, but the reality of Portland's hegemonic cyclist culture shows that his character reflects an exclusive and unequal cycling culture. In the next chapter, I consider how the physical geographies of cycling spaces in Portland serve to shape inequalities. I link larger inequalities in city planning to some of the ways in which these spaces reinforce or reinscribe racial and gender inequities. 
Chapter 5. Findings Part II: Unequal Spaces

In the previous chapter, I explored the many ways that marginalized cyclists face barriers and inequalities due to their gender and race. Cycling spaces are controlled by a larger hegemonic bike culture that favors an elite, white, and masculine spatial dominance. As evidenced by the data, cycling in Portland means routinely encountering gendered and racial spatial inequalities. However, as I will argue in this chapter, it is not merely that such inequalities are visible or amplified in cycling spaces in ways similar to other public spaces; cycling spaces themselves are physically built to exclude women and people of color. Not only are cycling (and city) spaces built to favor white, able-bodied men over marginalized populations, but multiple marginalized identities intersect in ways that amplify the inequalities within cycling spaces. I will illustrate this argument by describing intersectional issues that arose from the data which encapsulate intersectional cycling spatial inequality: Black masculinity, intersecting class inequalities, and the experiences of women of color. After that, I will discuss how it is not just the identities of cyclists that matter because the cycling spaces themselves are planned in a way to specifically support the hegemonic white masculine actor. Portland's history of racist and classist urban planning, and ongoing legacies related to this past were recognized by many participants in this study as part of why the cycling culture and community was perceived to be exclusionary. I will illustrate how people of color relate their biking experiences to larger forms of racism perpetuated by Portland and its racialized and classist history of urban planning. This will be demonstrated by reviewing the effects of Portland's racist public planning and its links to gentrification and displacement of 
cyclists of color. In addition, the ways that bike lanes are planned perpetuates masculine domination over white and nonwhite women.

\section{INTERSECTIONAL SPATIAL INEQUALITIES}

Despite the many common themes of spatial inequality that we can attribute to race or gender identity, these data were seldom related to only one marginalized identity: identities intersect to multiply marginalized cyclists' experiences. Spatial inequality is perpetuated for this sample by race, class, and gender hegemony that interlocks to create unique mechanisms of how male dominance is justified. The barriers described by participants all act as mechanisms of a spatial patriarchal white order. The mechanisms serve to benefit a masculine, white, and higher class group of cyclists and actors in public space. In the following section, I will focus on the explicit intersections and salient identities that stood out for this sample of infrequent and marginalized cyclists. By displaying the intersections of oppressions in this discussion, I hope to illustrate the pervasive nature of spatial inequality and the ways in which spaces are planned to marginalize certain populations.

The identities and layers of marginalization cumulate to multiply oppressed positions evidenced by people of color in this sample. Class interacts with many of my respondents, but some face economic instability more than others and cannot afford many resources associated with safe and quality biking. Samuel, along with feeling isolated as a Latino man in Portland, bikes as a means of transportation. He does not own much of the gear associated with avid cycling. Often during our interview, Samuel indicated that he 
does not have the money for better biking gear and that he goes without certain safeguards and comforts, such as a helmet and raincoat, because biking was never a choice for him; it's how he saves money. For Samuel, biking is a choice shaped by his class. He is acutely aware of his position as isolated, and perhaps looked down upon as a lower income individual:

You see the cyclist community and you think of this connotation of a white person. Like it's just a white centric bike culture, but again, there are people of color out there, but again, you hardly see them so you start to pretty much mesh that together, that it's just white people that bike. So, it's hard to think of outside what you're always seeing as pretty much what I'm going off of, it's just white people. Even when I was in California, yeah I did live in rural places but you would see people on their $\$ 2,000$ bikes just biking for fun on their long trips. They've got the shoes and everything that clip into the pedals, and when they got off you can hear them click-clack. Man, I bet those shoes cost more than what I spend on shoes in a year. [Laughs] So even coming from over there, it's different, because you do see people who pretty much have time where they use not biking as a transportation to get to work but more as a... I don't want to say a decompressor, but a luxury.

Samuel does not see cycling as luxury in his life, but a way to save a buck to get to work. He specifically sees the typical cyclist as someone who holds the affluence to treat cycling as a hobby, sport, or luxury. This class issue combined with his race/ethnicity makes cycling more difficult for Samuel to enjoy or access than it might for a white, affluent cyclist in Portland. Class operates to limit how low-income residents access public space, and the precautions they can afford to take to do so safely. Riding a bike in the rain without a helmet can be dangerous and hazardous, but as a low-income person, Samuel feels he has no other choice. Samuel also notes how cycling is associated with whiteness, which is an association he does not want for himself. Samuel does not altogether reject cycling; he finds enjoyment in his mobility on a bike, but he does speak 
to how cycling can be oppressive to someone who might otherwise choose to drive and not be scrutinized for their race or class by observers. As Samuel is multiply marginalized as a low income and Latino person, he cannot separate one form of marginalization to improve his experiences. Like Samuel, my participants are unable to change their interlocking identities that shape their barriers to cycling. Gender, race, and class intersect to produce pervasive injustices and benefit the dominant culture that benefits from this oppression (Collins 2000). Race and class are intrinsically linked to exclude participants like Samuel from fitting the mold of a dominating affluent and white cyclist.

Gender has been a salient identity among women participants in this research, but it compounds with many other identities. The mothers in this sample, for instance, cannot separate their identity as a parent with their identity as a woman cyclist. For participants like Evelyn and Julia, their body size and ability conflates the experiences they have as women, or feminine presenting persons in the case of Julia who is genderqueer. For the women of color in this sample, race is transformative for their experiences on a bike. Collins (2000) theorized that intersecting identities are interconnected and result in multiply dominated and oppressed personhood. Many women of color spoke of their experiences not only as women, nor as just their racial identities, but as Black, Latina, or Native women. These identities could not be separated, and in some instances, race was more salient that gender. Ana, a Latina woman mentioned above, recognizes that her race affects her cycling experience coupled with gender. She is able to distinguish what part of 
her multiple identities, gender, gives her empowerment on a bicycle more than the interconnected identity of race:

Talking about intersectionality, we're all these identities. But I definitely feel like my racial identity way more impacts my biking than like my gender identity, even those two are, you know, so interconnected and linked. I feel more empowered, I think, to bike as a woman than I do as a person of color.

Ana's experience reflects the ways in which marginalization is pervasive in cycling spaces. Despite empowerment she can draw from her womanhood, the construction of her gender and race identity cannot be separated. Robin notes the inherent nature of inequality by design in cycling spaces. To Robin, masculinity is painted in the bike lanes and the spaces themselves should be altered to reflect equality:

I think just that more community riding [would help], maybe not so individual... Because women don't ride in as large of numbers as men do. And the women that do ride are... they have to kind of be a little bit masculine to fit into the culture, so they're not getting run over. And so it's like women's business in the 80 's, I mean we had to wear ties and gray suits and ties to look like men, in order to be successful, to legitimize our presence in the workforce. And so there needs to be a way that women, in cycling, are legitimized that we belong here. It's for us too. And I mean, maybe that looks like a girl's lane and a boy's lane. Or maybe it looks like a fast lane and a slow lane. Or maybe there's a lane that's like it's okay to be who you are. You don't have to wear Spandex in this lane, or be skinny or, you know, be in the best shape you've ever been in. But I think the fact that women don't ride in as large of numbers is by design. I think it could be solved through design... [There is] man-spreading in the bike lanes. I wish there were gender specific lanes. I wish there were pink lanes and blue lanes.

Although gender segregation in the bike lanes would not be suitable for all genders (and beyond the binary), Robin does bring up a good point. Women do not fit into the culture, and bike lanes were not built for women. In this way, bike infrastructure can be exclusive. The design of bike infrastructure amplifies spatial inequality for women of 
color acutely in that they must interact with the oppressive nature of racial inequality while being a woman that does not fit into the spaces carved out for cyclists.

Furthermore, cycling culture and spaces produce unique issues relating to interconnecting oppressions for marginalized individuals. Because of the complexity of masculinity and the oppression of Blackness in the U.S., African American men face unique complexities in their mobilities. As established with issues of police and gun violence, Black men must fear possible police brutality and violence in their mobilization choices beyond only "Driving while Black" (Nicholson 2016). Black men have apprehensions in feeling safe in public space, but constructions of hegemonic masculinity make their choices even more complicated. Black masculinity might be considered especially salient in issues of cycling as there is a cultural barrier to modes of transport. Peter, an African American man, explains this well by describing the childishness Black men might feel is cast upon them if they choose to bike:

You know, there are fewer Black folks here, in Portland. Black folks... I think they would prefer to drive a car because it's convenient. It's comfortable. You can do many things. I mean, it's a very deep issue... though it is cheaper to have a bike than to have a car. But still I think for the social status, it looks better if you were to have a car rather then a bike. So I think that may play into it for... It means that most Black men, not riding a bicycle, that it's cheap. And so as a kid, yeah, it's probably okay. But if you're an adult, being a Black man, in particular... for a Black man who is an adult, riding a bicycle, it may give the appearance of childishness. And you know, Black men are very sensitive about their image because of historical content. So, having a bicycle for a Black American, it's very...I mean, I think we have to be very clear that we have to say Black Americans. Because other groups may have different take on that. So...But I think, because of the history in this country, I think for a Black man to ride a bicycle, it may not elevate your social status. [Chuckles] Whereas if you have a car, a nice car where you have, you know, it looks good, then people may think of you a little bit differently. 
Peter displays another way that historical racial inequalities acutely impact Black men's mobility choices with cultural norms. Not only does Peter indicate that a car is a better social status symbol than a bike, he unearths the negative connotations of childishness that threatens one's Black masculinity. What is left unsaid is that cycling in Portland castes a certain image on cyclists, one that may not be desirable to Black men, or men of color that do not fit the archetype of a hegemonic Portland cyclist. The spaces and its participants amplify spatial inequality for cyclists of color who cannot be seen in their preferred light when choosing to ride a bike. Some other participants of color in this sample indicated that they do not want to be seen as a white cyclist. Miguel, a Latino man, encapsulates this issue by saying, "I have to constantly have to be proving that I'm not biking because I'm doing something that white people do." For cyclists of color, their peers might perceive them as emulating white culture rather than celebrating their own. Due to historical trauma and racism in America, cyclists of color want cycling to be their own formation of mobilities, while not being associated with the mechanisms of spatial inequality that the elite and white cyclist perpetuates. These racist issues are also a reflection of Portland's urban planning choices and a history of segregation in Portland.

\section{PORTLAND’S RACISM \& HISTORICAL INEQUALITIES IN PLANNING}

Despite national praise (Bicycling.com 2016; McKenzie, 2014), Portland's reputation as bike-friendly does not mean that biking is accessible for all residents. Portland is a predominantly white city with a racially tense and deep history of redlining, segregation, and more recently, displacement and gentrification (Gibson 2007). In line 
with Portland's planning history, participants from this study link problematic planning practices at the city level to their experiences. Although progressive or democratic politics are shared by many Portlanders, and it houses many left-oriented nonprofits and organizations, Portland is not immune from perpetuating inequitable practices against marginalized groups. Race and class are factors that shape not only the interpersonal experiences of marginalized groups, but urban planning and investment. Portland's diversity has shrunk in the last decade as people of color are forced to move to the outer and more affordable neighborhoods of Portland from the inner and now gentrifying and costly neighborhoods of Portland (Hannah-Jones 2011). Portland has made choices such as new developments, bike lanes, and other investments that have contributed to gentrification and displacement (Gibson 2007; Lubitow and Miller 2013). Some of the aftermath from installing bike lanes and bikeways is described by participants who observed the effects that the urban landscape and population changes had on their communities.

\section{Marginalization \& Infrastructure Choices}

Seven participants in this study were African American/Black individuals who lived in North Portland ${ }^{2}$, namely, the Albina district that has been historically occupied by African Americans since the Vanport flood and redlining of the $20^{\text {th }}$ century (Gibson 2007). The history of Portland's racist city planning has not been forgotten by its residents today, especially those African Americans who live, or had lived, in historically Black Portland. The demographics and business ownership have been changing

\footnotetext{
${ }^{2}$ The seven participants who reside in North Portland (Albina district) are Robin, Jordan, Simone, Janae, Helen, Marcus, and Demetrius. The remaining African American participants resided in other areas of Portland.
} 
drastically in North Portland: beginning in the 1990s, Whites rapidly reclaimed housing in Albina neighborhoods, Black business corridors transformed into the "Alberta Arts District," and the area was no longer primarily inhabited by Blacks (Gibson 2007). Demetrius, the youngest participant in this study at age 19, grew up in historically Black North Portland and has seen the many changes that gentrification has made to his neighborhood. Like other residents of color, he is critical of how Portland chooses to prioritize its infrastructure spending. He begins by proposing that Portland hosts one of its popular neighborhood cycling events, Sunday Parkways, in one of the farther out and often ignored neighborhoods in East Portland. He explains the racialization of what kinds of neighborhoods Portland chooses to invest in based on his community's perspective:

Definitely having a Sunday Parkways or something in East Portland would superhelp. But I don't feel like the city cares about people of color biking at all. I mean, they barely care about people of color living in Portland... once you think about the historical things that Portland has done to gentrify the area, it's like all the things they're adding on feels like it's just part of the agenda... Even if they want to say, "Oh, it's not to displace people, it's just to help pedestrians and bikes." It's like, I don't even believe you anymore because, remember, you put in all this other infrastructure, like the MAX [train] and such, which helped displacement. So...I think, at this point, it's just [about] talking to people and being equitable in where we put these things in and not going off of demographics or how much property tax you can get if the housing prices go up. But thinking about the people because, yeah, there might be more people now that bike in North/Northeast Portland. But if you put bike lanes out in East Portland, then more people would bike. And so thinking like that, instead of where are people at now, thinking about what you can do to help people which I don't think there's enough of.

Demetrius points out that the bike lanes that have been implemented have accelerated the gentrification of North Portland which affects communities of color, but by adding bike lanes to farther out areas where other marginalized populations live, perhaps then cycling infrastructure could be accessible for others besides the affluent white cyclists moving 
into rapidly gentrifying areas. Those who are displaced from North Portland end up in areas such as outer East Portland where housing is more affordable yet infrastructure is lacking. Furthermore, there is a racial history of distrust in his statements: to residents of color like Demetrius, where bike lanes are placed represents a larger history of disregarding communities of color in urban planning (Gibson 2007; Lubitow and Miller 2013). As noted earlier, people of color in my sample felt a sense of invisibility in cycling; many felt that quality biking infrastructure was less accessible outside of white, affluent neighborhoods, contributing to the increased invisibility of people of color and the lack of attention to community needs. Thus, while people of color experience interpersonal racism while biking in Portland, racism also exists at a structural level in Portland. The infrastructure choices the city has made reflect a history of choosing the needs of white and affluent populations over people of color.

Demetrius touches on points that are echoed by other participants in this sample. People of color, especially Black participants, note how Portland's city planning does not consider people of color. Marcus, a Black man living in North Portland, adds that people from his community are being displaced to infrastructure-disadvantaged neighborhoods:

I don't think the city takes into consideration people of color. And the reason I say that is because in our neighborhood, North Williams was a historically Black neighborhood, for a very, very long time. And there was no bike-only lane, until gentrification kicked in. And then you saw all these changes happening. And you see this perpetuate throughout the city, you know. As gentrification happens, then you see road changes and bike routes and all these other conveniences happening. Where now, the Black community is being forced out to places like Gresham...[and] you don't see those things. You don't see bike routes like being carved into Gresham. You don't see that, you know. And you probably won't see it until there's an influx of young White millennials, you know that are buying property. You probably won't see that. So, no, I don't think they take that into consideration at all. 
Marcus raises a real concern for Portlanders in that bike lanes are reserved for privileged people and are not associated with neighborhoods that are several miles from the city center. Class (dis)advantage goes hand-in-hand with the displacement of people of color. As urban areas increase in their property values, the cost of housing rises, ultimately displacing lower-income communities of color who cannot compete with the level of affluence of white individuals of higher socioeconomic status who reap the benefits of urban growth and gentrification. Demetrius and Marcus illustrate the racial tension that is caused by Portland's urban planning and prioritization, but such changes also affect lowincome whites who are also displaced by gentrification.

The question of urban planning, bike lanes, and the displacement caused by gentrification raises questions about how Portland should continue to focus on bike infrastructure. On the surface, new biking infrastructure might appear as it is intended as a public good, yet it has been contested by those who see injustices in city planning (Lubitow \& Miller 2013). Rosa, a Latina woman, interrogates what bike lanes mean to white cyclists versus herself; to her, putting in bike lanes is a political choice made by the city:

This is about white cyclists. But I think this is also just white people and their perception of biking in general, where people, I think, will consider it politically neutral. Or any type of infrastructure related to biking is supposed to be positive. And I don't think I necessarily see it that way. It's like, I might benefit from a bike lane. But I think like also, you know, what if someone in Gresham needs to get into the center of Portland is disabled? And how is your bike lane going to help them? Like I think people maybe aren't as aware of those issues as I would like. But that's also Portland in general. Everyone is more racist than they think they are... 
Rosa raises an essential critique of Portland in that the infrastructure installation choices it makes, like adding bike lanes, do not reflect the needs of marginalized communities. In this sense, Portland may show preferences to those who want additional bike lanes and some residents may feel neglected by city planning choices. Marcus and Demetrius mention that people of color are being displaced to suburbs of Portland, such as Gresham or East Portland, and that those areas are treated as less of a priority than the city center. As Rosa alludes to, infrastructure placement can be related to larger issues of racism. This intersects with class in that populations in previously underfunded and now gentrifying neighborhoods cannot keep up with the increase in housing costs. Once marginalized communities are displaced, they are pushed further out of the city, away from the city center and farther from resources.

Rather than increasing cycling access in the outer neighborhoods where people of color and lower-income individuals are displaced to, Portland instead focuses on placing bike infrastructure in the inner city (Portland Bureau of Transportation Portland Neighborhood Greenways, 2015). As I argued earlier, cycling in Portland is typically associated with white, upper-middle class men, which is the population (along with white, affluent women) that typically has better access to housing closer to the citycenter, and more robust transit choices. By ignoring marginalized communities in designing the urban landscape, Portland can be perceived as taking a political stance to favor historically privileged communities (Gibson 2007). By not facilitating change and resources for marginalized groups, Portland sends a message to these populations that it will not design the city for their diverse needs. Not only do marginalized cyclists have to 
face the day-to-day interpersonal barriers to cycling from the bike culture, they also have to navigate being physically carved out of it or excluded by design.

Furthermore, marginalized groups represented in this sample also note the priorities that Portland bypasses by prioritizing cycling infrastructure. When the city of Portland opts to install bike lanes, some participants from this study feel that Portland simultaneously chooses to not fund other areas that need infrastructure such as sidewalks or street lamps. These funding decisions made by city planners are observed by the marginalized residents they affect while the new bike lanes or bike boxes in North Portland are celebrated by affluent consumers who patronize new bars and restaurants on North Williams Avenue. Indeed, biking infrastructure can, and does, positively impact these communities, but only those who are fortunate enough to remain close to Portland's city center. On that note, because marginalized communities want to further participate in cycling, including their voices in cycling infrastructure is key to improving cycling equity. As Rosa points out, the changes being made in cycling infrastructure is by white people, for white people, which cannot coexist with Portland touting that it is bikefriendly, let alone diverse and equity-centered. Changes need to be made in Portland to increase cycling rates among underserved populations such as women, people of color, and lower-socioeconomic citizens. The city of Portland must take an active part in this, and its citizens have ideas on how to widen the scope of who can and will bike in Portland.

In this chapter, I reviewed the racialized city planning that creates spatial inequality specific to people of color in Portland; larger issues of displacement and 
gentrification shape barriers to cycling for communities of color. In the following chapter and discussion, I will contribute positive aspects of cycling based on narratives from marginalized cyclists. I will then discuss policy implications suggested by the participants synthesized with implications from the policy review literature. Following that, I will discuss what all of my findings mean in the context of cycling spatial inequalities and the previous literature. 


\section{Chapter 6. Discussion}

\section{So Why Bike? Love of Cycling}

Finally, throughout the negative experiences voiced by these participants in the previous chapter and section, there is a reason they continue to bike or did bike for a time: a love, or enjoyment, of cycling and its benefits. Even though cycling may not be a top priority for all in this sample, there are a variety of reasons that people choose to bike regardless of the barriers they face. Indeed, marginalized cyclists often want to increase their cycling, and indicate that if the barriers were mitigated, they would do so. This section will highlight the benefits of cycling shared by interviewees.

For some participants, cycling can bring convenience for people living in an urban area. For Carla, there's a simple efficiency that comes with biking: "Looking at traffic, looking at struggling to park, and just sliding my bike right through, that makes the whole bike riding experience worth it." Carla is talking about the convenience that comes with arriving and parking by bike rather than driving through hectic traffic and having difficulty with finding a space to park a car. Portland offers ample bike racks in many neighborhoods, especially in and near the city center. Many participants shared Carla's appreciation of the ease of parking a bike in many otherwise busy places in Portland, and reflected on the cost benefits of avoiding paying for car parking. Although oftentimes people in this sample reported the ease of driving over cycling, they simultaneously noted that when they do bike, it seems much easier than other forms of transportation. 
Carol echoes the sentiment of the convenience of cycling and avoiding driving. She finds that she has more peace of mind while biking over driving and joy in not having to measure distance in traffic. Biking can alleviate stress, especially when it means avoiding city traffic. She also enjoys the freedom and individuality of riding a bike by herself:

[I] like going at my own pace, and... it's kind of reflective to ride a bicycle and just be really absorbed and watching everything around and not have to think like, oh, where's that other person? Oh, they're really far ahead. Or they're really far behind. Or wait, they have to stop for something. And I mean, sometimes it's fun to ride with another person and talk. But I think those are two different experiences and they're both good. But riding by myself is like being a bird.

In another section of her interview, Carol shared that cycling is nostalgic for her, and that is like being a free child all over again. Not only does cycling feel whimsical and freeing, it also feels like a sense of individuality for Carol in not having to worry about others' speed. This sentiment is similar to the previous chapter discussion on agency that cycling can provide women; in this sense, cycling can be enjoyed more than driving because its liberating physically and in one's mind.

Elizabeth, a 60-year-old white woman, was the oldest person in this sample while also being the only person in this sample to self-describe as a 'fearless cyclist.' Initially, Elizabeth chose to bike for recreation and health reasons, yet her cycling has transitioned into some light commuter use as she now does some grocery shopping on her bike. Elizabeth has the potential to become a utilitarian cyclist. Elizabeth persists in her choice to bike while acknowledging that cycling in her area can feel unsafe due to a lack of infrastructure and problematic motorist behavior. For her, cycling is her right and her own form of freedom despite the unpopular routes she takes: 
I just want to go someplace. I feel I have a right to do that. And I have a right to be on the street. And if it doesn't have a bike lane, chances are it's not going to be very fun to be there. I might have to go on a street like that... like Glisan [Street], which is at the other end of my street. And not only that, but they have those bump-outs for storm water. And then it just... There's no sidewalk. There's no nothing... I just want to get some place. And I'm a law-abiding citizen. And I try to be obvious. And I exercise my right to go there, like these people get in their cars and, unless they get a speeding ticket they're free to go where they want to go. (Chuckles) And I like to do it. It's exercise, even if it's like going to the grocery store. I go, well, I might buy a bunch of food. But some of it I'm exercising off.

Along with Elizabeth's boldness in where she will take her bike, and the freedom she gains from cycling, there is another layer of class disadvantage to where she bikes. Elizabeth lives in far east Portland, not unlike displaced people of color, where rents are cheaper but infrastructure is lacking: although Elizabeth self-categorizes as a fearless cyclist, she still realizes the danger of biking on major streets such as Glisan where the cars move fast, there are no bike lanes, and no sidewalks. As stated earlier, Portland's infrastructure planning choices affect marginalized groups' accessibility to cycling. Elizabeth might only brave her bike route in East Portland because she feels especially brave, bold, or fearless without more cycling infrastructure.

In conjunction with the freedom these cyclists embrace while cycling, some express feeling a positive interaction with space. Unlike driving, cyclists can take in the scenery of the landscape they might normally speed past, and unlike walking, you can reach farther destinations in less time. This positive interaction with space, like freedom, is associated with independence and agency, as Peter reflects on:

When I bike, I like to see what people are up to. I like people. I like watching people. So as I bike I just like to observe the scenery. So, I mean, I like the feeling of biking because it gives you a lot of control. It gives you a good sense of 
independence. So I love that a lot... so that's why I really don't like driving because it takes away from that independence.

Like Peter, a lot of cyclists in this sample enjoyed the community feel of riding amongst other cyclists and pedestrians. Cycling offers a slower pace of life than driving does, and allows more access to spaces that are not meant for motorized vehicles such as parks or promenades. It also offers a mode of transport that exposes you to the beauty of the scenery and nature. Samuel adds that not only do you get where you are going on a bike, you have less constrictions than driving a car:

It's good to feel the crisp air on your face sometimes, and it's a good way to decompress honestly. I prefer to ride during the day but I do ride at night sometimes. I don't know, you just ride faster to get to your destination because... again, it's exhilarating, just this adrenaline rush like... Oh man, you're not constricted to the driving lanes, like, “oh, what's down that street? I don't know but I'm going to go find out because I'm on a bike and I can make a turn so easily".

Samuel, despite riding bike primarily for utility, can see the benefits of cycling over driving. He has fun and feels exhilaration riding his bike rather than the stress and constraint of driving. This positive interaction with space is not something that is granted with driving in the same way. Although driving offers different forms of recreation or relaxation, cycling offers the unique exercise and decompression while transporting oneself faster than walking.

As illustrated through the data and many reported benefits of cycling, there are many reasons to be optimistic and strive for cycling access and equity. Biking means many things to different people, but commonly it is associated with freedom, exercise, convenience, and positive interactions with public space. In the previous chapter, I explored how community was important to cyclists, and with community comes 
socializing with others. Unsurprisingly, participants in this study called for change that centered the voices of the community for methods of increasing cycling.

\section{POLICY AND SOLUTION RECOMMENDATIONS}

Policy Review

Although systematic reviews of cycling interventions to promote ridership and increase access have been compiled (Pucher, Dill, and Handy 2010; Stewart, Anokye, and Pokhrel 2015; Yang et al. 2010), none have identified interventions specific to increasing ridership among marginalized groups. Research has established that building bike lanes and other biking infrastructure in urban settings acts as an attraction to existing bicyclists rather than creating new cyclists in the implementation area (Schoner, Cao, and Levinson 2015). However, the infrastructure research still suggests optimistic findings for large-scale infrastructure and policy projects in communities. From 14 city-wide infrastructure and promotional campaigns, Pucher et al. (2010) establish that comprehensive and complementary policies increase cycling more so than individual interventions that are not coordinated across an area. Individual-level interventions can increase cycling, but do not have the large impact that community interventions do (Pucher et al. 2010). Yang et al. (2010) contribute to policy reviews by evaluating research articles that targeted cycling rates as a dependent variable using an exhausted review of literature from 13 databases. Their findings establish that community-wide activities such as large promotional campaigns, city-wide infrastructure improvement, or targeted campaigns in workplaces and schools have the potential to increase cycling rates 
more so than individual-level measures; Yang et al. also establish that these findings work better for areas with already developed cycling cultures (2010). These data can be applied to Portland's robust cycling community to create positive change for marginalized cyclists.

Finally, the newest systemic review of cycling policy is as recent as 2015 with Stewart et al.'s research. In this study, multiple studies are examined which target understanding policy that increases commuter cycling (or non-recreation cycling): in this way, they contribute to Yang et al.'s (2010) research by looking to specific forms of cycling like commuter cycling. Like the other research, individual and group level policies and interventions are measured, but they also include environmental interventions. Environmental interventions are changes to the environment to promote active transport in everyday life, such as building bridges or stairs. Environmental interventions had small, but positive, effects and Stewart et al. (2015) suggest that the environmental interventions can benefit public health more so than group or individual level interventions: the reason being that the environment has a larger population of people it can reach than individual or group based interventions, as environment implies infrastructure that is accessible to all residents in a community.

All of the reviews discussed in this section examined several countries, including the United States. They all targeted cycling as a form of active transport, or, a way to implement physical exercise into one's daily travel routine. The implications of these policy reviews are that cycling equity should be tackled at a community level with tactics such as infrastructure improvements, promotional and marketing campaigns, and 
implementing bike-friendly policies in institutions that reach citizens and employees alike such as welcoming biking as transport to work, school, or other important locations of societal and cultural discourse and meeting. As Stewart et al. (2015) find, environments matters for interventions.

\section{Changing Portland Cycling: Policy That Centers Voices \& Other Solutions}

As Portland already has an established and robust cycling community compared to most U.S. cities, Portland can benefit from environmental interventions more readily and easily. Environment quality is likely a large part of the reason that Portland has thrived in the cycling world: its mild climate and roads have made for ample room for infrastructure improvement in recent years. However, its current community-level interventions are questionable and need further research. The Barriers to Bicycling and Four Types of Cyclist reports have begun this work, yet community interventions remain questionable. Marginalized cyclists had some ideas on how to encourage cycling for marginalized groups and break down barriers to biking. Solutions broadly revolved around changing the bike culture, increasing representation and inclusivity, community building, and increasing safe cycling education for drivers and cyclists. In my previous chapter, I elaborated on the many ways that people of color are made to feel invisible amongst the cycling culture in Portland. Based on these findings, participants formed ideas on how to make cycling more accessible and less exclusive.

Steps should be taken towards diverse representation in cycling. Samuel, a Latino participant, mentioned in the earlier chapter that he feels scrutinized as a person of color who bikes and that he sees only white people represented on cycling advertisements in 
Portland, saying: "Go Green. Bike to work. White person on the ad." The lack of representation is a common issue for participants in this sample, not only in the bike lanes, but in images. Increased representation of cyclists of color is a key solution in my findings. For example, Simone reflected on how increased representation of cyclists of color might encourage her and others to bike more:

Simone: Representation is everything. I tell my kids that, I tell everybody that. It's the same thing like watching T.V. growing up. When I grew up there wasn't any Black people on T.V., not until the Cosby's. Maybe there was a couple of shows, but representation is a big thing, and I think that if people saw more, people of color riding bikes, that would encourage them. And it'd be like, "oh... I should get a bike."

Interviewer: But do you think that you personally are affected by that?

Simone: I think so. Because I mean, there's been times where I was like, "Oh, I should take my bike?" [But I made a lot of excuses not to]... All of these excuses because I don't see any Black people riding bikes, so why should I ride a bike? And then I started seeing people of color riding... a couple of weeks ago I saw this Black lady and she had her helmet and everything... she was going to work, she rode her bike or whatever. Yeah, I think it does, it has affected me a little also... I think a huge part of it is that you don't see it. If you saw it more then you would probably be more open to doing it yourself. Like "Oh, let me go dust off my bike!"

Just by seeing another Black woman cyclist in Portland, Simone considers biking more. More positive impacts could be made on marginalized cyclists by increasing their representation, such as through advertisements, biking events, and targeting the membership of diverse riders in cycling organizations.

Along with representation, building community can solve some of the barriers to biking for participants in this sample. One way to do this is to introduce bike communities to other facets of life such as meetups, bike groups and clubs, and 
workplace biking partnerships. Robin offers her idea of what would incentivize her to bike commute to work more often:

I applied for a job at a company once... here in Portland, where they would come and send a [public transit] buddy on your first day of work. One [employee] would come by your house and show you the bus route to get downtown... at least for me, I would love to have a bicycle buddy. And I would love to have a female bicycle buddy that would say, "Oh, there's this great trench coat I found [to bike in]" you know, or...you know, try this cape. This is really cool." Or let's just go together. Because we can do it together.

For Robin, biking can be about social bonding which would further incentivize her to commute. This echoes many sentiments of the power of community cycling from my sample.

As illustrated above, participants had notions on how to improve their ridership in Portland. There is a need for a cultural shift and city intervention. The most consistent suggestion for large-scale change was policy and interventions that center marginalized groups voices in future planning, namely, people of color. Marcus, who earlier spoke of racist urban planning, thinks the first step towards positive change for cyclists of color is providing opportunities to participate in planning:

Just have an open dialogue that involves people of color, because it's their community, you know. You know, it's our community... so to make decisions without our input isn't inclusive. And I don't think it's equitable.

As explored earlier, Marcus attributes bike lanes with affluence and whiteness unlike displaced communities of color with fewer infrastructure options. To increase equity, we as residents need to listen to all communities in Portland. Helen, although slightly optimistic about the potential Portland has, remains critical due to the complicated barriers that marginalized cyclists face. She asks if Portland is trying to build solidarity for cyclists, and is it worth it: 
And, you know, Portland is trying, obviously. There's lots of groups that are like trying... [to] have open conversations and projects like this that are like, let's talk about this for real so that we can actually do something, not pat ourselves on the back because we're the kind of people that talk about it but because we can actually find a way to do something. I don't know if the answer is just more education or what. It's ridiculous that so much of this is like, all we're trying to do is make it normal to be different. It should not be this kind of mountain. Like, people live here. They get around on bikes. That should be the end of it. And instead, there are all these nuanced, weird, subtle barriers where you don't understand why it feels like there are speed bumps. And then you have this horrible, gnawing feeling that it's all in your mind until you get it validated by people in your community. And then you're like, well, what are you going to do? They're not going to bike. Or they will bike. Is this like a movement now? Are we building biking solidarity?

Helen raises a larger point here regarding barriers to biking for people of color: they can be confusing and isolating. Helen is cognizant of the inequalities she faces in riding a bike. Her concerns have been validated by her community, which raises the question of marginalized cyclists who are unaware that they are not alone. Without the community connection, there would be less awareness of the way that racism, classism, and misogyny affect people's access to various modes of transport and public spaces. Her testimony highlights the significance of giving voice to communities, and the exhaustion that marginalized individuals might feel in having to jump through extra hoops just to have safe and healthy access to something normal like riding a bike. By pushing for community action, Portland can push for community awareness. Marginalized cyclists, or marginalized individuals with the potential to own and ride a bike, could form the words to bond a community together, increasing their feelings of representation and safety.

Unlike white, affluent residents of Portland, communities of color have to raise a louder voice in order to have their needs heard. Often, it seems, their voices fall on deaf ears. To increase ridership among marginalized riders, including women, lower-class 
individuals, and people of color, the city must take direct action in including their voices in city planning. Perhaps this cannot start with building more bike infrastructure in neighborhoods that displaced residents are being pushed to; perhaps it must start with installing sidewalks and streetlamps before bike lanes. But once the city treats marginalized groups as a priority as they do the white and affluent, cycling might become a better transport option as a result of a safer culture and infrastructure.

\section{Policy Implications}

There are plenty of policy and infrastructure implications for this study. First, a public report should be written for the City of Portland, which could reach beyond the scope of an academic perspective. Public sociology has the potential to make policy impacts; by sharing this research, program funding could be initiated or expanded for equitable cycling in Portland. My thesis contributes to the knowledge about barriers to cycling in Portland. Other Portland specific history such as its racism can be brought into the forefront of the cycling discourse. If these findings were to reach the community, it could increase activism or advocacy among residents. Rather than focusing on the loudest voices of avid cyclists, city planning could hone its focus in on marginalized residents' voices. Giving voice to a community of potential cyclists could increase access to safe cycling and its diversity. To make Portland truly bike-friendly, I've argued that increasing its diversity is key.

My findings can inform some of the gendered and racialized issues for certain communities within Portland based on large-scale policy review data. Yang et al. (2010) found that community-oriented interventions of cycling are more likely to successfully 
promote cycling than individual measures. These policy evaluations have implications for Portland as it already has a cycling-centric culture and reputation, thus a potential to improve its communities' cycling rates. Stewart et al.'s (2015) evaluation of environmental impacts bodes well for Portland as its infrastructure thrives compared to many other cities. For example, Portland has implemented more bicycle boulevards than most cities in the U.S., alongside Berkeley and Palo Alto, CA (Nabti, J.M., Ridgway, M.D., 2002). When considering policy improvements from my findings on marginalized cyclists' experiences, the community-based issues should be examined carefully. Besides Portland's unique cycling culture, the demographic disparities can and should be address nationwide, as well as with other countries, which calls for qualitative research to interrogate the nuances and complications members of the community face, and quantitative research to interrogate those findings for causal effects. On the bright side of some dismal data, Portland is not completely unaware of its lack of diversity problem. The City of Portland plans on increasing its bicycle ridership from $10 \%$ to $25 \%$ by 2035 and to reach "all Portlanders" (Community Cycling Center 2012). There are also organizations in Portland that are capable of procuring funding and facilitating volunteer work and community partners towards local public health issues such cycling equity. The report "Communities of Color in Multnomah County: An Unsettling Profile" has findings that can provide us with hope that Portland community workers and researchers are putting in the labor and research towards equitable solutions. At the same time, the report points out one of Portland's dangerous issues: self-congratulation in our public discourse (Curry-Stevens, Cross-Hemmer, and Coalition of Communites of Color 2010). This is 
one of many reasons to interrogate Portland's reputation as a bike-friendly city, as well as understanding community-level interventions: the Portland community may appear bikefriendly, but as evidenced in this thesis, communities within the city face inequitable access to safe and equal cycling.

Safety was a large concern among participants. Oftentimes, participants addressed their fears and anxieties of riding near motorists, such as cars and buses. Education for drivers was suggested to address proper etiquette for sharing the road with cyclists. Furthermore, to address all the accounts of fear and harassment from women, interventions that center the complicated gendered barriers for women are a necessity. Often women reported that they felt safety in numbers as well as enjoying social riding; facilitating women's bike clubs and riding groups, as well as events centered around family riding, could increase safety and ridership for marginalized cyclists. Due to the micro aggressions faced by women and people of color in this sample, as well as threats of violence or harassment, Portland would benefit from implementing bystander training courses. Bystander training, cycling groups, and events could improve women's confidence in cycling. Women in this sample called for education targeted towards male riders and all motorists to make cycling spaces more welcoming and safe. Interventions should also be made available to the community of men in Portland: how to coexist with women in the bike lane and not block their access with discrimination and harassment. Although the data on race associated with cycling is limited, we do know that representation of cyclists of color has been low and problematic. For Portland, this is especially tricky: with so few people of color, how can we represent cyclists of color to 
encourage them to bike more? We can only start by turning to the community intervention data: cyclists of color should be represented on promotional ads, and targeted for institutional help. Samuel specifically stated earlier his unease with only white people on biking campaign posters. Space should be made for all marginalized cyclists to thrive and be together while they access cycling. The more diverse cyclists that get in the lanes, the more comfortable marginalized individuals might feel by being surrounded by more demographics than white men.

Lastly, environmental interventions should be considered more carefully in the city of Portland. As Lubitow \& Miller (2011) found, some communities of color are wary of biking infrastructure coming through their neighborhoods as gentrification can be associated with better cycling infrastructure. Communities of color should be first given voice before assuming any environmental changes they may want. Overall, voice should be given to marginalized communities before assuming interventions. Social programs that focus on community voice is one of many ways to start these interventions. Indeed, state and federal money should be provided for social programs that center around health and environmental impacts. Portland is on its way to do this, but more work addressing specific issues marginalized cyclists face needs proper research before we can proceed further.

DISCUSSION: GENDER, RACIAL, AND SPATIAL INEQUALITY WITH CYCLING Summary of Major Findings 
When IFC aired their Portlandia sketch featuring Fred Armisen as a quirky cyclist in Portland, the character's representation of cycling might have been taken as farce by its audiences. But Armisen's character fits into the mold of what marginalized cyclists classify as the hegemonic Portland cyclist. When Armisen's character moves through cycling spaces, he does so without regard of the cars around him, and is determined to own the space around him. His kooky character is a slightly exaggerated reality for marginalized cyclists in Portland. The Portlandia cyclist dominates cycling spaces: if he were a real Portland cyclist, you might see him ride aggressively next to not only cars, but other cyclists. He is merely the embodiment of spatial inequality. Marginalized cyclists from my sample do not bike infrequently simply because they prefer to. They facebarriers to cycling shaped by larger systemic inequalities that favor the white male cyclist over them. Armisen's cyclist character is not encumbered by childrearing duties, nor is he expected to take on the tasks of motherhood. He does not fear public crime or violence in the same way that women and people of color do. He does not realize his role in the larger scheme of the gentrification and urban development of Portland. He enjoys cycling at whatever frequency works for him. Marginalized and infrequent cyclists are negatively impacted by the oppression of their identities of gender, race, class, and other marginalized identities. Cycling spaces renew these systemic forms of oppression and control, and should be analyzed as another realm of inequality for marginalized populations. In order to increase bike ridership among women and people of color, we must consider the exclusionary and unequal spaces and access they face. 
Results from this study show that women's barriers to cycling are shaped by larger mechanisms of gender oppression, including gendered expectations of child rearing, fear of public spaces and the threat of harassment, and an underrepresentation of women cyclists leading to isolation from the cycling community. For women, cycling is an extension of larger social and cultural dynamics. By studying forms of spatial inequality, we see the pervasive nature of gender inequalities. Child rearing is one facet of gender expectations that translates to spatial inequality for women. Traditional gender roles in the family and workplace shape mothers travel behaviors (Creswell and Uteng 2008). Furthermore, the duties of childrearing lead to encumbered movement for mothers riding bikes, meaning there are physical limitations to what they can do as a result of gendered expectations. In the case of marginalized cyclists, mothers ride infrequently because of their gendered daily and travel routines that impact their choice and ability to realistically choose biking. This helps us understand the infrequency with which women may ride when they are tasked with duties of motherhood.

Feminist geography illustrates that women are acutely impacted in their use of public space by fear of crime and harassment. Valentine calls the inhibitive nature of women fearing crime in public spaces the "geography of fear" (1989). This concept is illustrated concisely when Carol, a Latino woman from my sample, says that she decides where to bike based on her "lady's map of the city;" she demonstrates how she feels unsafe and restricted in her mobilities by choosing not to bike to certain neighborhoods at night. This research echoes recent work by May et al. (2009) in suggesting that avoidance behaviors restrict mobilities: when women must consider where it is dangerous for them 
to bike, they often choose to avoid certain neighborhoods, or biking, altogether. Hegemonic masculinity assists in explaining the mechanisms of a patriarchal order of cycling spaces: the culturally embedded nature of masculinity (Connell 2005) is further embedded in cycling spaces as a means of male domination. Connell's idea can be extended to the dominating nature of male cyclists in Portland. The hegemonic bike culture consists of elite, white, and male cyclists, like the fit and hipster archetypes, that excludes marginalized cyclists. Dominant imagery, physical domination and entitlement to space, and aggression maintain the hegemonic bike culture. Men maintain power and domination over women to their benefit by fostering unwelcome and exclusionary cycling spaces: the archetypes of male cyclists are seen as the dominant and ideal type of cyclists, one that does not invite marginalized cyclists to the "clique" as Angela puts it. Due to their heightened visibility when biking, women experience aggression as a form of masculine domination of bike lanes and bike spaces. Furthermore, women are sometimes discriminated against in bike shops. Women's bodies are subjected to the male gaze, scrutiny, and harassment merely by riding their bikes. From a lifetime of gendered experiences, women have a perception of threat, meaning they fear crime, violence, or harassment, which translates to fear in public spaces; this is no different while cycling. Men perpetuate the norms of women's fear and avoidance behaviors through violence and the male gaze (Green et al., 1990, Lupton, 1999; Pain, 2001). This research agrees with feminist geographical findings that describe the scrutiny, catcalling, and street harassment women face in public spaces, and contribute that cycling is no exception to the gendered rule. A few women from this sample had experienced 
harassment or catcalling on their bikes. To attempt to avoid these issues and dangers, women adhere to a geography of fear and which acts as a sort of second consciousness that alerts women where they should or should not go, when they should ride, and what visibility they will subjected to depending on their clothing choices.

My findings also show how cycling spaces are unequal due to racial inequality. People of color in this sample echoed the larger sentiments made by white women: fear of space and underrepresentation. But for people of color, fear of space meant fear of profiling and police. One participant, Marcus, spoke to the national epidemic of police on Black violence as a barrier to feeling safe in Portland. His experiences agree with studies that show how racial violence controls Black men's mobilities (Nicholson 2016). Underrepresentation of cyclists of color indicates a larger demographic difference in Portland, but it was found that racism shapes the resulting barriers to cycling. Women of color felt scrutinized as women cyclists which intersecting with racist controlling images of femininities of color (Collins, 2000). As Janae put it, she feels she must be hyper vigilant and aware of her color on top of her femininity. All of this compounds with people of color being aware that they do not fit the mold of an "average" Portland cyclists who is a white male. With these data, we see how fear of public space is not only gendered, but racialized, and participants are acutely aware of their racial minority status in a majorly white city. Spatial inequality is thus shaped by race in that cyclists of color harbor fear in cycling spaces as they do in urban spaces due to racist attitudes. Moreover, they are excluded from the hegemonic bike culture, and their underrepresentation may 
perpetuate spatial inequality for cyclists of color in that they do not have power in numbers when entering biking landscapes.

Furthermore, spaces are unequal in ways that reveal intersectional and interconnected oppressions for marginalized cyclists. Cycling spaces present issues that are intersectional such as those experienced by Black men, low-income individuals, and women of color. Because the spaces are not built for marginalized people, marginalized cyclists face more difficulty fitting into the spaces and the culture. Racialized spaces are an example of how spatial inequality is shaped, and varies, by the context of the space. For Portland, this means that cyclists of color attribute their cycling disparities to larger city planning issues. In Portland, gentrification and displacement has disproportionally affected African Americans in NE Portland for the last few decades (Gibson 2007; Shaw and Sullivan 2011; Sullivan and Shaw 2011; Sullivan 2007). Communities of color in general are disproportionally affected by economic vulnerability as houses are priced and targeted towards white and affluent families (Curry-Stevens, Cross-Hemmer, and Coalition of Communities of Color 2010). My participants agree with the research by Lubitow and Miller (2013) which contends that what the city marks as a public good can have large and unjust impacts on people of color. While people of color from my sample might see the benefits of cycling, they are concerned with the city's preference for the elite and white cyclist population. Thus, spatial inequality is shaped by Portland's planning and spaces themselves: when the city chooses public planning without regard of the needs of communities of color, they imbed racial exclusion into the cycling spaces. When bike lanes are built in areas like North Williams Boulevard, participants are 
reminded daily of the effects of gentrification and white residency. To people of color, Portland shapes their exclusion from city spaces.

\section{Contributions to the Literature}

This research is the first of its kind to examine cycling disparities as a result of spatial, gendered, and racial inequalities through conducting qualitative interviews. Women's cycling rates fall below men's in the U.S. and other industrialized nations, and women have different behaviors and attitudes towards cycling than men do (Akar et al. 2015; Bopp et al. 2012; 2014; Fischer and Namgung 2013; Garrard et al. 2008; Garrard et al. 2012b; McKenzie 2014; Steinbach et al. 2011). These data are reflected in Portland's cycling demographics despite national praise for commuter rates (Community Cycling Center 2012; Dill and McNeil 2013; Garrard et al. 2012b). Moreover, ridership disparities for people of color are underexplored in terms of data collection and analysis, and there are national cycling rate disparities among racial and ethnic groups (Community Cycling Center 2012; McKenzie 2013; 2014; Curry et al. 2010). My thesis interrogated the missing link between gender, race, and spatial inequalities for cyclists. Using the scholarship of feminist geography and racial dynamics within urban planning, I linked bicycling as an issue of gender and race inequalities in public space.

\section{Limitations}

This research is not without limitations. To begin, it contains a restricted sample, leading to a lack of comparative analysis with white men. With more funding and time, this thesis could have entailed not only interviews with women and people of color, but also with white men to incorporate their own narratives. Comparing white men's cycling 
experiences would contribute to understanding how inequalities can be perpetuated by non-marginalized persons; the comparisons could also offer points of similarity between my participants and their white male counterparts. A different research method for comparing the complex gendered, racial, and classed experiences would be focus groups. Women, people of color, and white men could voice their concerns about cycling as unified forces to stimulate conversation and rich data. Future studies could try alternative methods such as comparative analyses and focus groups.

As this sample was only 28 participants, results are limited and cannot determine causality unlike that of certain quantitative analyses with larger populations. Due to its qualitative nature, my findings are not generalizable outside of the setting of Portland, Oregon. Moreover, the disadvantage of having a diverse yet small sample is the diminishment of demographic representation; the issues founded by the 10 white women in this sample may not represent other white women in Portland, for example. Because of Portland's unique bicycle scene and largely white population, other cities' cyclists will have differing experiences with infrastructure and populations. Indeed, some participants mentioned that they felt their cycling experience in Portland was unique compared to other cities. This study could increase its transferability with the help of quantitative, or mixed methods, analysis. A nationally representative survey such as the National Household Travel Survey could serve as a vehicle for large data on barriers to cycling if adjusted accordingly to question cycling behavior.

Finally, this study suffers from the low representation of sexual and gender minority voices. Despite all efforts to make this project truly intersectional and inclusive 
to all marginalized individuals, conducting a qualitative research project is nevertheless difficult without some forms of exclusion in recruitment. Although some LGBT, genderqueer, and trans individuals participated, they were small in number. For the purpose of this research, it was theorized that LGBT identities may not be visible on a bike whereas gender and race identities are often immediately identifiable by those interacting with cyclists. When recruiting, I made note that 'self-identifying/Trans women' were welcome to participate, however, this language is still exclusive to individuals who align outside of the gender binary and Trans Men. White Trans Men might have felt excluded from this study as the only men welcome to participate were men of color. This study would benefit from adding LGBT identities as another intersection for theoretical purposes, and especially gender non-conforming or Trans individuals who might present their gender in alternative ways compared to women and men in this sample.

\section{Strengths}

This research contains many strengths, the first being that it fills a gap in the literature. This study is the first of its kind that uses feminist methodology to investigate intersectional inequalities among cyclists. This research contributes to the literature by adding empirical data conducted under the theoretical framework of intersectionality and feminist geography. In addition to its unique methodology, this research contributes data about people of color's cycling experiences. More feminist research is needed with an intersectional approach, encompassing diverse races, ethnic groups, and lower educational and income levels in a variety of fields such as cycling. Understanding 
marginalized groups' cycling habits will illustrate what barriers to cycling remain for minority populations and lead to policy implications to make cycling an equitable travel behavior in the United States. Filling the research gap can also inform policy interventions for urban cycling planning, practices, and priorities. This research will contribute to the literature on transportation habits of marginalized groups in Portland, Oregon. It is my hope that this research will help facilitate more equity discourse by The City of Portland. It would elate me to see my findings reach the marginalized residents of Portland; perhaps a small change could be made towards equitable cycling by reading about others' experiences. Beyond contributing to the academic literature, perhaps this research and others like it could inform public sociology, social change, and bike activism in the Portland area. 
References

Abelson, Miriam J. 2014. "Dangerous Privilege: Trans Men, Masculinities, and Changing Perceptions of Safety.” Sociological Forum 29(3):549-70.

Acker, Joan. 2006. "Inequality Regimes: Gender, Class, and Race in Organizations." Gender \& Society 20(4): 441-464.

Akar, Gulsah, Nicholas Fischer, and Mi Namgung. 2013. "Bicycling Choice and Gender Case Study: The Ohio State University." International Journal of Sustainable Transportation 7(5).

Aldred, Rachel, James Woodcock and Anna Goodman. 2015. "Does More Cycling Mean More Diversity in Cycling?” Transport Reviews 1647(July):1-17.

Bicycling.com 2016. "The 50 Best Bike Cities of 2016” Retrieved April 1, 2017. (http://www.bicycling.com/culture/news/the-50-best-bike-cities-of-2016/slide/2)

Bopp, Melissa, Andrew T. Kaczynski, and Gina Besenyi. 2012. "Active Commuting Influences among Adults." Preventive Medicine 54(3-4):237-41.

Bopp, Melissa, Stephanie Child, and Matthew Campbell. 2014. "Factors Associated with Active Commuting to Work Among Women.” Women \& Health 54(3): 212-231.

Buehler, Ralph and John Pucher. 2012. "International Overview: Cycling Trends in Western Europe, North America, and Australia." In: John Pucher and Ralph Buehler (Editors), City Cycling. MIT Press, Cambridge, MA.

Connell, R. W. 2005. "Hegemonic Masculinity: Rethinking the Concept." Gender \& Society 19(6):829-59.

Crenshaw, Kimberlé. 1991. "Mapping the Margins: Intersectionality, Identity Politics, and Violence against Women of Color." Stanford Law Review 43(6):1241-1299.

Choo, Hae Yeon and Myra Marx Ferree. 2010. "Practicing Intersectionality in Sociological Research: A Critical Analysis of Inclusions, Interactions, and Institutions in the Study of Inequalities.” Sociological Theory 28(2):129-49.

Community Cycling Center. 2012. "Understanding Barriers to Bicycling Project, Final Report.” Portland, OR. Community Cycling Center.

Curry-Stevens, A., Cross-Hemmer, A., \& Coalition of Communities of Color (2010). "Communities of Color in Multnomah County: An Unsettling Profile." Portland, OR. Portland State University. 
Cresswell, Tim., and Tanu Priya Uteng. 2008. Gendered mobilities: Towards an Holistic Understanding. In Gendered mobilities, ed. T. Cresswell and T.P. Uteng, 1-12. Burlington, VT: Ashgate Publishing Company.

Dill, Jennifer and Nathan McNeil. 2013. "Four Types of Cyclists? Examination of Typology for Better Understanding of Bicycling Behavior and Potential." Transportation Research Record: Journal of the Transportation Research Board 2387: $129-38$.

Emond, Catherine, Wei Tang, and Susan Handy. 2009. "Explaining gender difference in bicycling behavior." Transportation Research Record 2125(1): 16-25.

Epstein, Cynthia Fuchs. 2007. "Great Divides: The Cultural, Cognitive and Social Bases of the Global Subordination of Women." American Sociological Review 72(1):122 .

Garrard, Jan, Chris Rissel, and Adrian Bauman. 2012a. "Health Benefits of Cycling." In: John Pucher and Ralph Buehler (Editors), City Cycling. MIT Press, Cambridge, MA.

Garrard, Jan, Susan Handy, and Jennifer Dill. 2012b. "Women and Cycling." In: John Pucher and Ralph Buehler (Editors), City Cycling. MIT Press, Cambridge, MA.

Garrard, Jan, Geoffrey Rose, and Sing Kai Lo. 2008. "Promoting transportation cycling for women: The role of bicycle infrastructure." Preventive Medicine 46 (1): 5559.

Gibson, Karen J. 2007. "Bleeding Albina: A History of Community Disinvestment, 1940-2000.” Transforming Anthropology 15:3-25.

Glenn, Evelyn Nakano. 1994. "Social Construction of Mothering: A Thematic Overview." Pp 1-29 in Mothering: Ideology, Experience, and Agency, edited by E.N. Glenn, G. Change, and L. Forcey. New York: Routledge.

Green, Eileen and Carrie Singleton. 2006. "Risky Bodies at Leisure: Young Women Negotiating Space and Place.” Sociology 40(5):853-71.

Grosz, Elizabeth. 1992. "Bodies-cities.” Pp. 241-254 in Sexuality and Space, edited by B. Colomina. New York: Princeton Architectural Press.

Hannah-Jones, Nikole. 2011. "In Portland's Heart, 2010 Census Shows Diversity Dwindling." The Oregonian. Retrieved April 1, 2017.

(http://www.oregonlive.com/pacific-northwestnews/index.ssf/2011/04/in_portlands_heart_diversity_dwindles.html). 
Heesch, Kristian C., Shannon Sahlqvist, and Jan Garrard. 2012. "Gender Differences in Recreational and Transport Cycling: A Cross-Sectional Mixed-Methods Comparison of Cycling Patterns, Motivators, and Constraints." International Journal of Behavioral Nutrition and Physical Activity 9(1):106.

Collins, Patricia H. 2000. Black Feminist Thought. New York, Routledge.

Huy, C., S. Becker, U. Gomolinksky, T. Klein, and A. Thiel. 2008. "Health, Medical Risk Facors, and Bicycle Use in Everyday Life in Over-50 Population.” Journal of Aging and Physical Activity 16 (4): 454-65.

Longhurst, Robyn. 2005. "Situating Bodies." Pp. 337-349 in A Companion to Feminist Geography, Vol. 6, Blackwell Companions to Geography, edited by L. Nelson and J. Seager. Malden, MA: Blackwell Pub.

Lorber, Judith. 1994. Paradoxes of Gender. New Haven: Yale University Press.

Lubitow, Amy and Thaddeus R. Miller. 2013. "Contesting Sustainability: Bikes, Race, and Politics in Portlandia." Environmental Justice. 6(4).

Mapping Police Violence. 2017. “Police Violence Map.” Retrieved June 1, 2017 (https://mappingpoliceviolence.org).

May, David C., Nicole E. Rader, and Sarah Goodrum. 2010. "A Gendered Assessment of the threat of Victimization' ': Examining Gender Differences in Fear of Crime, Perceived Risk, Avoidance, and Defensive Behaviors." Criminal Justice Review 35(2):159-82.

McCall, Leslie. 2005. "The Complexity of Intersectionality." Signs: Journal of Women in Culture and Society 30(3):1771-1800.

McKenzie, Brian S. 2013. "Neighborhood Access to Transit by Race, Ethnicity, and Poverty in Portland, OR." City and Community 12(2):134-55.

McKenzie, Brian S. 2014. "Modes Less Traveled: Commuting by Bicycle and Walking in the United States," 2008-2012, American Community Survey Reports, ACS-26, U.S. Census Bureau, Washington, DC, 2014.

Miralles-Guasch, Carme, Montserrat Martínez Melo, and Oriol Marquet. 2016. "A Gender Analysis of Everyday Mobility in Urban and Rural Territories: From Challenges to Sustainability." Gender, Place \& Culture 23(3): 398-417

Nabti, J.M., Ridgway, M.D., 2002. "Innovative bicycle treatments: An informational report." Institute of Transportation Engineers (ITE), Washington, DC. 
Nicholson, Judith A. 2016. "Don't Shoot! Black Mobilities in American Gunscapes." Mobilities 11(4):553-63.

Oja, Pekka, Sylvia Titze, Adrian Bauman, Bas de Geus, P. Krenn, B. Reger-Nash, and T. Kohlberger. 2011. "Health benefits of cycling: a systematic review."

Scandinavian Journal of Medicine \& Science in Sports 21: 496-509.

Pain, Rachel. 1997. "Whither Women's Fear? Perceptions of Sexual Violence in Public and Private Space.” International Review of Victimology 4(4):297-312.

Pain, Rachel. 2001. "Gender, Race, Age and Fear in the City." Urban Studies 38(56):899-913.

Portland Bureau of Transportation. 2015. "Portland Neighborhood Greenways Map." Retrieved April 1, 2017 (https://www.portlandoregon.gov/transportation/50518).

Preston, Valerie and Ebru Ustundag. 2005. "Feminist Geographies of the "City": Multiple Voices, Multiple Meanings.” Pp. 211-227 in A Companion to Feminist Geography, Vol. 6, Blackwell Companions to Geography, edited by L. Nelson and J. Seager. Malden, MA: Blackwell Pub.

Pucher, John, Jennifer Dill, and Susan Handy. 2010. "Infrastructure, Programs, and Policies to Increase Bicycling: An International Review." Preventive Medicine 50:106-25.

Pucher, John, Ralph Buehler, and Mark Seinen. 2011. "Bicycling Renaissance in North America? An Update and Re-Appraisal of Cycling Trends and Policies." Transportation Research Part A: Policy and Practice 45(6):451-75.

Schafer, Joseph A., Beth M. Huebner, and Timothy S. Bynum. 2006. "Fear of Crime and Criminal Victimization: Gender-Based Contrasts." Journal of Criminal Justice 34(3):285-301.

Schoner, Jessica E., Jason Cao, and David M. Levinson. 2015. "Catalysts and Magnets: Built Environment and Bicycle Commuting." Journal of Transport Geography 47:100-108.

Steinbach, Rebecca, Judith Green, Jessica Datta, and Phil Edwards. 2011. "Cycling and the City: A Case Study of How Gendered, Ethnic and Class Identities Can Shape Healthy Transport Choices." Social Science \& Medicine 72(7): 1123-1130.

Stewart, Glenn, Nana Kwame Anokye, and Subhash Pokhrel. 2015. "What Interventions Increase Commuter Cycling? A Systematic Review.” BMJ Open 5(8). 
Thomas, David R. 2006. "A General Inductive Approach for Analyzing Qualitative Evaluation Data." American Journal of Evaluation 27(2):237-46.

Tran, Marc. 2015. "Combatting Gender Privilege and Recognizing a Woman's Right to Privacy in Public Spaces: Arguments to Criminalize Catcalling and Creepshots." Hastings Women's Law Journal 26(2):185-206.

Valentine, Gill. 1989. “The Geography of Women’s Fear.” Area 21(4):385-90.

Valentine, Gill. 2007. "Theorizing and Researching Intersectionality: A Challenge for Feminist Geography.” The Professional Geographer 59(1):10-21.

Wen, Li Ming, and Chris Rissel. 2008. "Inverse Associations Between Cycling to Work, Public Transport, and Overweight and Obesity: Findings From a Population Based Study in Australia." Preventative Medicine 46: 29-32.

West, Candace and Don H. Zimmerman, 1987. "Doing Gender." Gender \& Society 1(2):125-151.

Yang, Lin, Shannon Sahlqvist, Alison McMinn, Simon J. Griffin, and David Ogilvie. 2010. "Interventions to Promote Cycling: Systematic Review." BMJ 341(c5293):1-10. 
Appendix A. Screening Survey

Qualtrics Survey found at tinyurl.com/psubikeresearch

1. How would you describe your gender?

2. What is your home zip code?

3. What is your age?

4. When the weather IS nice, how often do you ride your bike in a typical week? Select one:
a) 1-2 times
b) 3-5 times
c) $6-8$ times
d) 9 or more times
e) Fewer than 1 time a week
f) 0 times

5. When the weather IS NOT nice, how often do you ride your bike in a typical week? Select one:
a) 1-2 times
b) 3-5 times
c) $6-8$ times
d) 9 or more times
e) Fewer than 1 time a week
f) 0 times

6. Were you ever a "frequent" cyclist (biked several times a week)? Select one:
a) No, I'm a beginner
b) No, I've never used my bike more than a couple of times a week
c) Yes, I used to bike several times a week or more (at some point in life)
d) Not since I was a child
e) Not sure (explain): 
7. What is your race/ethnicity? Select one:
a) White/Caucasian
b) African American
c) Hispanic/Latino
d) Asian
e) Native American
f) Pacific Islander
g) Other

8. What is your employment status? Select one:
a) Unemployed
b) Part-time
c) Full-time
d) Retired
e) Other

9. What is the highest degree or level of school that you have completed? Select one:
a) Less than high school
b) High school diploma or GED
c) Some college or technical school, no degree
d) Completed college or technical school, with a degree or certificate
e) 4-year degree / Bachelor's degree
f) Graduate study currently in progress
g) Completed graduate degree (e.g., master's, PhD, MD)

10. Please enter your name and contact information below. Further details on the study (including schedule and location) will be emailed to those selected for interview participation. If the research team is unsuccessful in contacting you at the e-mail you provide we will attempt to reach you by telephone. Type:
a) First name
b) Last name
c) E-mail address
d) Phone number 
Appendix B. Interview Guide

\section{Introduction}

1. How long have you lived in Portland?

a) If you moved here recently-what brought them to Portland?

2. What part of the city do you live in?

3. What's your favorite thing about living in this city?

4. Can you walk me through a typical day in your life? What do you do and where do you go?

a. What types of transportation do you use? Does it change between weekday and weekend?

\section{Biking Behavior}

1. What kind of bike do you have? Where do you store your bike?

a. Do you have bike accessories?

2. Describe an average or typical bike riding experience for you

a. How do you think your experience compares to the average Portland cyclist?

(Whatever you think the average Portland cyclist is? What do they look like?)

b. What kind of clothes do you wear while biking? (Raingear, casual, etc.)?

3. Besides the typical ride you described, what are some other places you might go (or have gone) on your bike?

4. Do you ride bikes with people? If so, how often, and who?

5. Is there a particular time of day that you prefer to ride?

a. When do you avoid riding? Do you ride at night?

6. Do you feel safe while cycling?

7. Do you bike with your family or children?

8. How does the weather impact your riding habits?

\section{Experiences:}

We are interested in knowing how your experiences shape your views on cycling, more specifically, how your identities impact how you view biking.

1. What makes riding your bike a positive experience for you? Do you have a specific memory?

a. Prompt: Who was present? Time of day? Feelings/specifics that made it positive?

2. What makes riding your bike a negative experience for you? Do you have a specific memory?

a. Prompt: Who was present? Time of day? Feelings/specifics that made it negative?

3. How do you feel other cyclists and pedestrians affect your experience?

a. Prompt: How do you interact with them if you do? Positive or negatively?

4. How do you feel your gender shapes your experiences when you are biking?

a. Prompt: What are the positives/benefits of your gender in cycling in Portland? 
b. Prompt: What are the negatives/disadvantages of your gender in cycling in Portland?

5. How do you feel your race shapes your experiences when you are on your bike? a. Prompt: What are the positives/benefits of your race in cycling in Portland?

b. Prompt: What are the negatives/disadvantages of your race in cycling in Portland?

6. Are there any other individual traits you feel affect your cycling experiences?

a. Prompt: (follow up on other parts of their identity they might have mentioned-class, sexuality, disability/injuries, body)

\section{Barriers}

1. What prevents you from biking more?

a. (Prompt: is it an equipment issue, a social issue, an infrastructure, or other?)

2. Would you like to ride more?

a. Since you said that you would like to bike more: what would help you do so?

b. Since you said you would not like to bike more: what would make you want to bike more?

3. What is your ideal cycling situation?

4. How does being in Portland shape your cycling experience?

a. Does the city of Portland do anything to help people like you bike more? Should it do something else?

5. Is there anything else that you would like to tell me? 